\title{
FLASH - A FINITE ELEMENT COMPUTER CODE FOR VARIABLY SATURATED FLOW
}

\author{
Robert G. Baca \\ Swen O. Magnuson \\ Subsurface and Environmental Modeling Unit \\ Geosciences Group
}

\section{May 1992}
Idaho National Engineering Laboratory EG\&G Idaho, Inc.
P. O. Box 1625
Idaho Falls, Idaho 83415

Prepared for the

U.S. Department of Energy

Office of Environmental Restoration and Waste Management Under DOE Idaho Field Omice Contract No. DE-AC07-76ID01570

\section{MASTrR}




\begin{abstract}
A numerical model was developed for use in performance assessment studies at the INEL. The numerical modeh referred to as the FLASH computer code, is designed to simulate two-dimensional fluid flow in fractured-porous media. The code is specifica!ly designed to model variably saturated flow in an arid site vadose zone and saturated flow in an unconfined aquifer. In addition, the code also has the capability to simulate heat conduction in the vadose zone. This report presents the following.'

$o$ description of the conceptual framework and mathematical theory,

$o$ derivations of the finite element techniques and algorithms,

o computational examples that illustrate the capability of the code, and

$o$ input instructions for the general use of the code.

The FLASH computer code is aimed at providing environmental scientists at the INEL with a predictive tool for the subsurface water pathway. This numerical model is expected to be widely used in performance assessments for: (1) the Remedial Investigation/Feasibility Study process and (2) compliance studies required by the U.S. Department of Energy Order 5820.2A.
\end{abstract}




\section{Table of Contents}

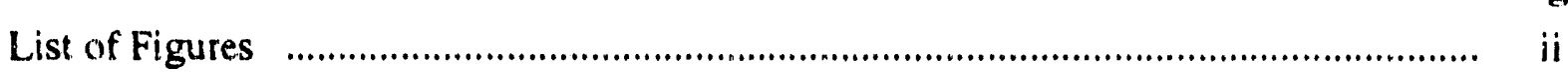

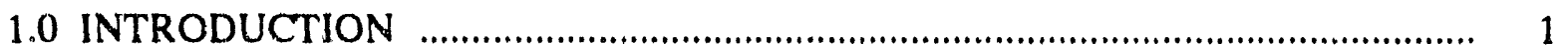

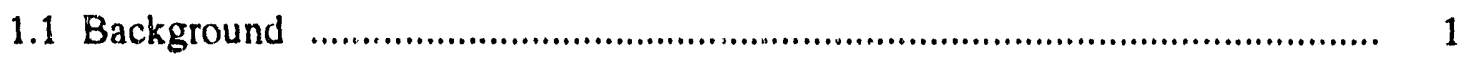

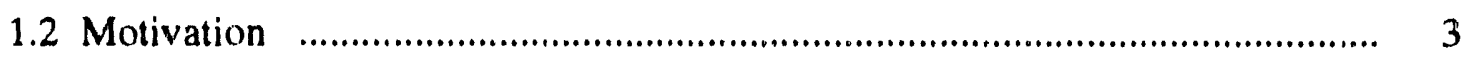

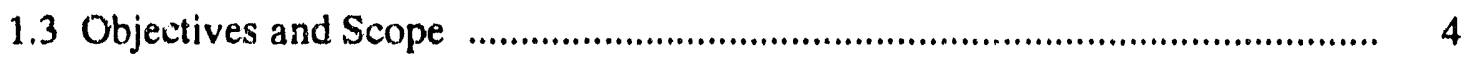

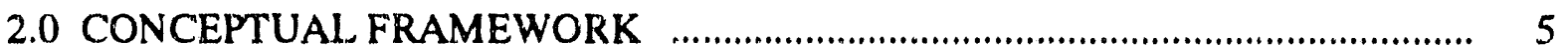

2.1 Physical Setting .................................................................................... 5

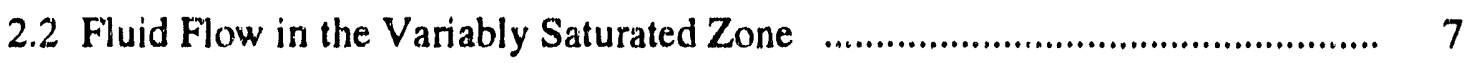

2.3 Fluid Flow in a Free Surface Aquifer ........................................................ 8

2.4 Heat Transport in the Soil ........................................................................ 8

3.0 MATHEMATICAL MODELS AND ASSUMPTIONS ................................... 10

3.1 Introduction ........................................................................................... $\quad 10$

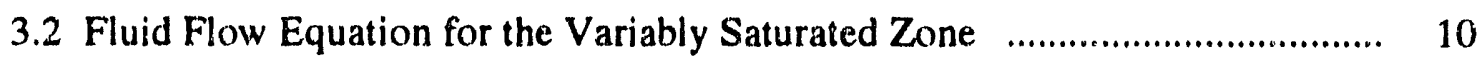

3.3 Fluid Flow Equations for a Free Sirface Aquifer ....................................... 11

3.4 Heat Transport Equation for the Vadose Zone ............................................ 12

4.0 FINITE ELEMENT FURMULATION ...................................................... 14

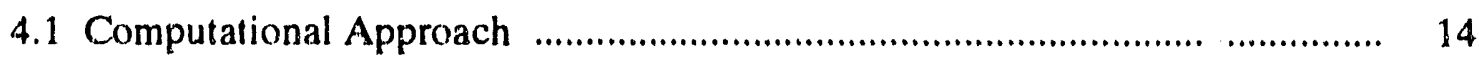

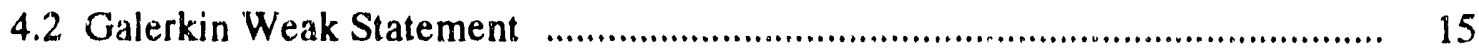

4.3 Newton Based Weak Statement ................................................................... 19

4.4 Picard Based Weak Siatzment .............................................................. 20

4.5 Time Integration Scheme ..................................................................... 22

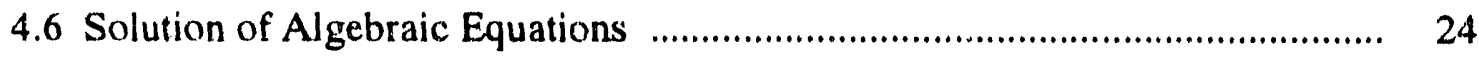

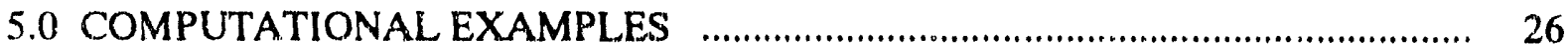

5.1 Partially Saturated Flow in a Dry Soil ...................................................... 26

5.2 Saturated-Unsaturated Flow in a Two-Dimensional Domain ....................... 30

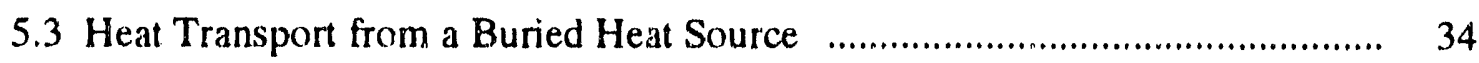

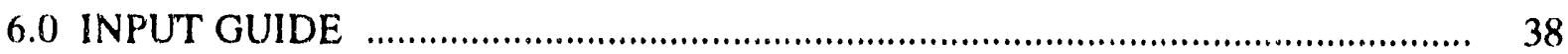

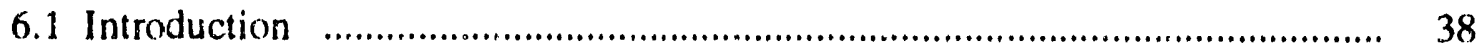

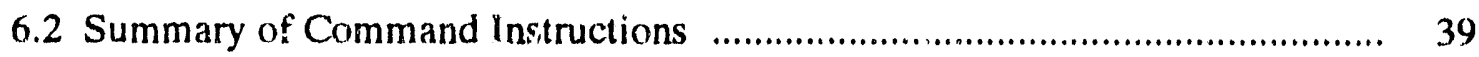

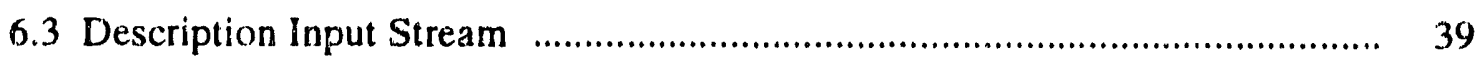




\section{Table of Contents (Continued)}

ACKNOWLEDGMENTS Page

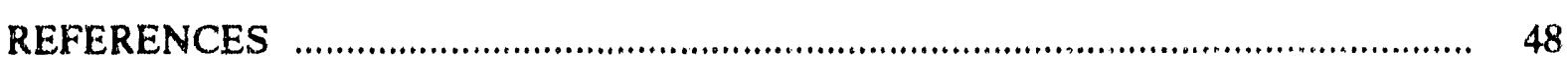

APPENDIX I - SAMPLE INPUT FILES FOR TEST PROBLEMS ………............... 52

DISTRIBUTION LIST ……....................................................................... 58

\section{List of Figures}

1 Location of INEL, Site and Facilities …….................................................... 2

2. Conceptual Sketch of Physical Setting ............................................................. 6

3 Types of Finite Elements used in Consiructing a Computational Mesh _............ 14

4 Superposition of Finite Elemenis ……….................................................. 16

5 Domain and Boundary Conditions for Variably Saturated Flow Problem .......... 26

6 Comparison of Pressure Head Profiles computed with FLASH and UNSAT1D codes

7 Comparison of Moisture Content Profiles computed with FLASH and

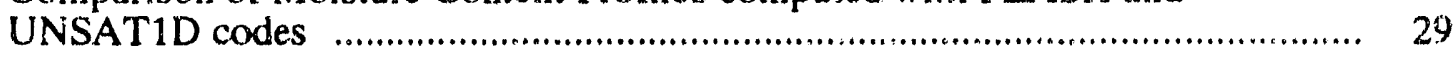

8 Domain and Boundary Conditions for Saturated-Unsaturated Flow Problem ..... 30

9 Comparison of Pressure Head Profiles computed with FLASH and PORFLO-3 codes

10 Comparison of Moisture Content Profiles computed with FLASH and PORFLO-3 codes

11 Domain and Boundary Conditions for Heat Transport Problem ……................. 34

12 Comparison of Soil Temperature Distributions computed with FLASH and Analytical Solution

13 Sample Finite Element Mesh 


\subsection{INTRODUCTION}

\subsection{Background}

Environmental activities at the Idaho National Engineering Laboratory (INEL) include evaluating low-level radioactive, hazardous and mixed-waste sites at such facilities as the Radioactive Waste Management Complex (RWMC), Test Area North! (TAN), Test Reactor Area (TRA) and others, see Figure 1. These evaluations are being conducted as part of: (1) the Remedial Investigation/Feasibility Study (RI/FS) process and/or (2) compliance studies required by the U. S. Department of Energy (DOE) Order 5820.2A. An important part of these evaluations, referred to as the performance assessment, is the analysis of contaminant movement from waste sites through the atmospheric, biotic, and water pathways.

At the INEL, like other DOE sites, the water pathway is the most significant (Case, et al., 1989, RAE, 1990). Because of the absence of natural, surface-water features at the INEL, these performance assessments generally focus on the issue of contaminant movement through the subsurface, i.e., vadose zone and Snake River Plain aquifer. Specific attention is given to:

o identifying the hydrologic factors and geochemical mechanisms controlling contaminant transport,

0 assessing the rate, direction and extent of movement, and

o predicting the contaminant concentrations in subsurface environment.

With this information, informed decisions can be made regarding the selection of alternative actions for site clean-up and environmental restoration.

Numerical models are playing a central role in performance assessments at the INEL because of their usefulness in predicting migration of dissolved and colloidal phase contaminants. An important prerequisite, however, is the analysis and interpretation of pore-water movement in the subsurface. In the vadose zone, for example, moisture movement must be related to such factors as: (1) infiltration and/or liquid discharge rates, (2) natural driving processes, eg., capillarity and gravity, and (3) hydraulic properties of distinct stratigraphic features. Similarly, water movement in the saturated zone or aquifer must be described as a function of: (1) recharge and discharge rates, (2) hydraulic gradients and properties, and (3) groundwater dynamics associated with pumping wells at neighboring sites. 

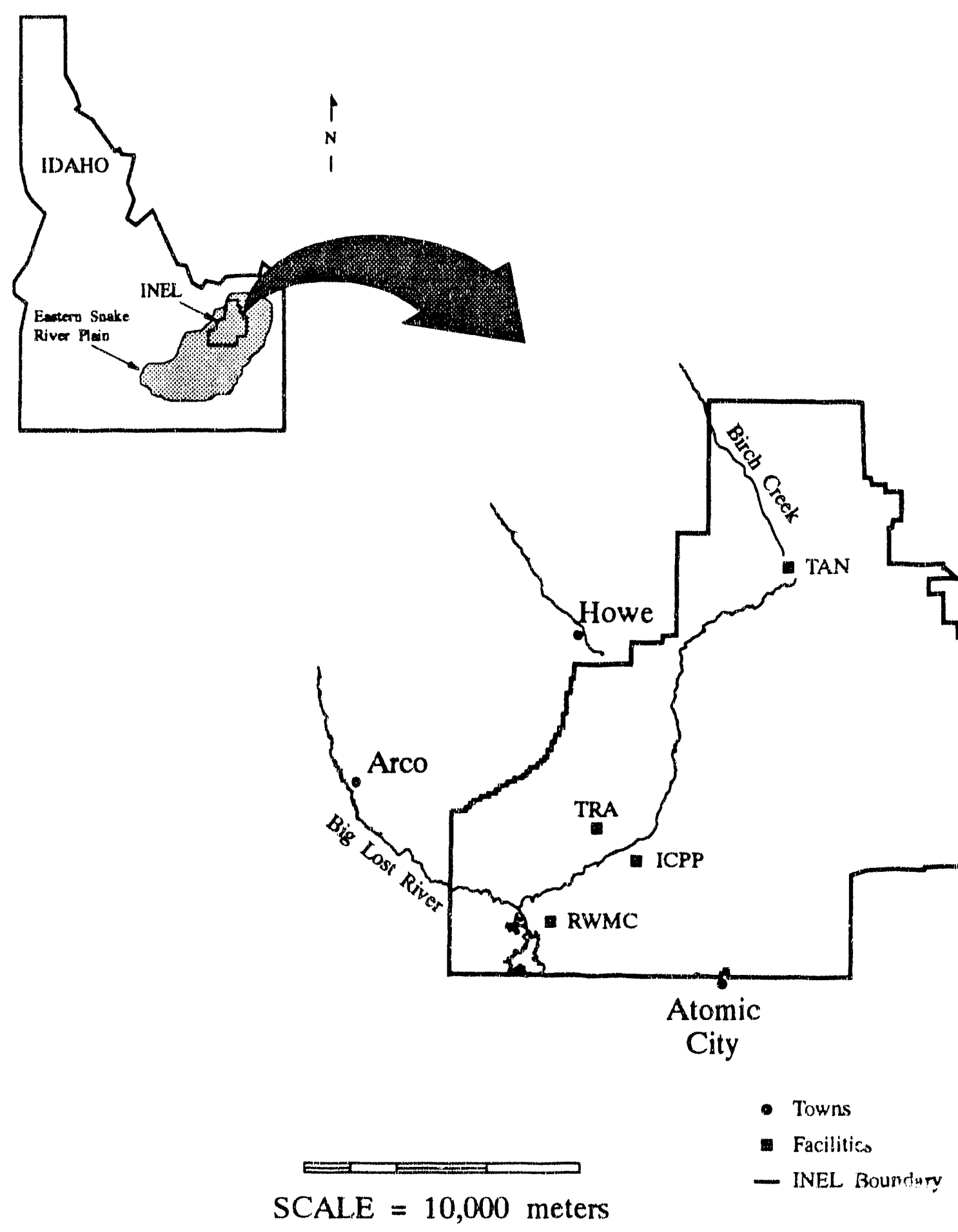

Figure 1. Location of the INEL Site and Facilities 
Flow and transpoit modeis were originally developed for use in performance assessments of waste sites at the RWMC. Recently, these models were generalized for application to other facilities at the INEL. This report describes a finite element, fluid flow model referred to as the FLASH computer code. This numerical model is designed for use in simulating two-dimensional, variably-saturated, single-phase flow and heat conduction in the vadose zone; these processes are modeled for an arbitrary, vertical cross-section. The code also has the capability to simulate saturated flow in the unconfined aquifer; flow in the aquifer is modeled in the horizontal plane taking into account the changes in water level elevation. The FLASH computer code is interfaced with a companion numerical model referred to as the FLAME computer code. The FLAME code uses the flow computations from the FLASH code and then simulates contaminant transport in the subsurface. The FLAME code is documented in a separate report.

\subsection{Motivation}

A large number of numerical models have been developed by the scientific community for the purpose of predicting subsurface fluid flow and contaminant transport. These numerical models are described in the literature (Bachmat, et al. 1980; Oster, 1982) and are available through the International Groundwater Modeling Center, the National Water Well Association, and other sources. Many of the existing models, however, were developed for specific applications and therefore have distinct limitations. For example, many of the available models are limited in that they:

0 are not applicable to both vadose zone and unconfined groundwater flow,

o do not work well when applied to arid sites,

o do not have a contaminant transport capability,

$o$ are not applicable to fractured-porous media, and/or

o do not accommodate strata with complex geometry.

Recent code testing and code benchmark studies (Magnuson, et al, 1991; Baca and Magnuson, 1991) performed at the INEL suggests that relatively few, truly general, models currently exist. Moreover, many of the existing models have limited documentation, have not been independently verified or benchmark tested, and/or are not maintained under a software $Q A$ or configuration control program. Such limitations place in question the predictive reliability of these numerical models, and therefore, on the conclusions drawn in a performance assessment. 
To avoid potential model limitations and questions of reliability, the FLASH code and its counterpart FLAME were developed for general use at the INEL. Both codes are extensions and refinements of the MAGNUM fluid flow code (Baca and Langford, 1986; England, et al., 1986) and CHAINT contaminant transport code (Baca and Langford, 1986; Kline, et al., 1986); these computer codes were originally developed by the principal author for groundwater studies at the Hanford Site. The FLASH and FLAME computer codes are maintained under a formal software control procedure (Baca, 1990). The source codes have been thoroughly tested using the INEL's CRAFT and FORWARN FORTRAN analyzers. In addition, these codes are currently being independently verified and benchmark tested by researchers at Washington State University.

The development of the FLASH code is aimed at providing environmental scientists with a versatile and reliable predictive tool. Thus numerical model, and its counterpart, are expected to have wide applications to performance assessments and environmental restoration studies at the INEL.

\subsection{Objectives and Scope}

The primary objective of this report is to provide formal documentation for the FLASH computer code, Version 3.0. The scope of the documentation includes:

o a description of the conceptual models for which the numerical model is applicable,

o discussion of the mathematical theory and assumptions,

o derivations of the numerical techniques and algorithms used in the code,

o presentation of computational examples to illustrate the capability of the numerical model, and

o input instructions for general use of the computer code.

Input files for computational examples are presented in an appendix and can be used to gain familiarity with the use of the FLASH code. 


\subsection{CONCEPTUAL FRAMEWORK}

The applicability of a numerical model to a particular physical system greatly depends on the completeness and correctness of the assumed conceptual model. A conceptual model, as used here, is a description of the: (1) unique physical features and properties of the natural system that influence its behavior, (2) the physical processes and coupling effects that control the system response, and (3) the fundamental assumptions that are made in formulating the mathematical models. The conceptual framework used in developing the FLASH computer code is presented in this section.

\subsection{Physical Setting}

Arid sites, such as the INEL, NTS and Hanford, are highly attractive for waste disposal because of ideal climatic conditions, thick vadose zones and low average annual precipitation, eg., $20 \mathrm{~cm}(-8 \mathrm{in})$ or less. At such sites, the average annual infiltration into the geologic setting can be quite low, eg., less than $10 \mathrm{~cm}(\sim 4 \mathrm{in})$. Under these conditions, the surficial sediments can provide a high degree of isolation to waste buried in shallow pits, trenches and soil vaults. However, the occurrence of several and closely spaced precipitation events can result in pulses of infiltration, which in turn, may enhance waste migration. A scenario of concern at the INEL is a combination of events such as warm winds, rapid snowmelt and heavy rains that produce water ponding and infiltration (Vigil, 1988).

To model subsurface flow phenomena at the INEL, the geologic setting is conceptualized as: (1) thick vadose zone composed of thin surficial sediments and a sequence of basalt strata with interbedded sediments and (2) a deep saturated zone composed on fractured-porous basalt strata, see Figure 2. The basalt strata constitutes about 95 percent of the geologic profile. Individual basalt flows generally exhibit considerable structural and textural variation and are heterogeneous, anisotropic, fractured-porous media. At certain sites, such as the RWMC, the basali geology is reasonably well characterized (Anderson and Lewis, 1989; Knutson, et al., 1992).

Data compiled by Knutson, et al. (1992) indicate that basalt flow thicknesses vary from $.31 \mathrm{~m}(1 \mathrm{ft})$ to $17.2 \mathrm{~m}(56 \mathrm{ft})$ with an average of $4.6 \mathrm{~m}(15 \mathrm{ft})$. These authors define the generic elements of a typical basalt flow as consisting of: (1) top vesicular zone, (2) rentrai zone, and (3) bottom vesicular zone. In general, the vesicular zones have significantiy higher permeability than the central zone. Observations by Rightrrire and Lewis (1987) suggest that fracture infilling material was transported through interconnected fracture networks. 


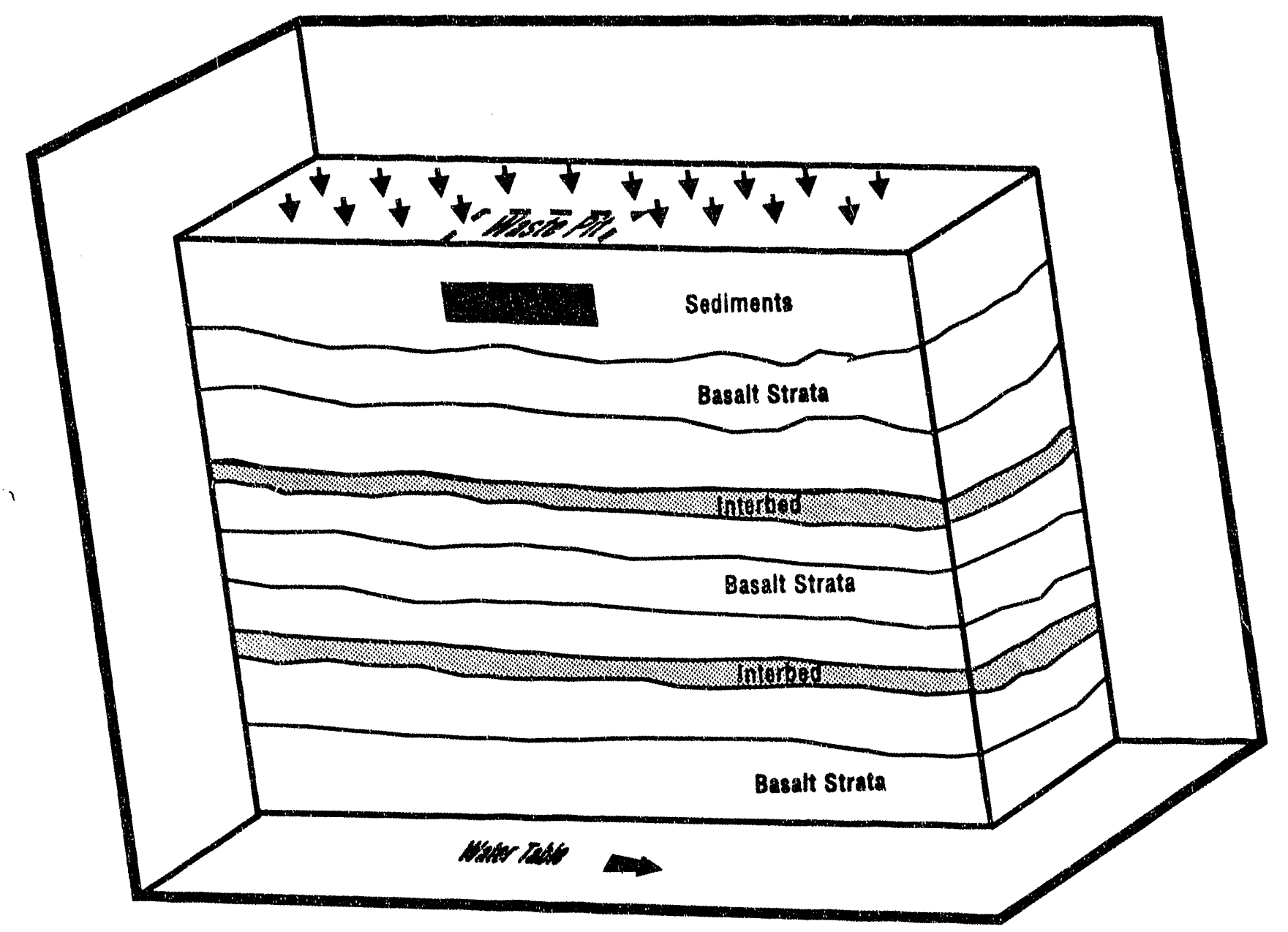

Figure 2. Conceptual Sketch of Physical Setting

The void structure of the basalt flows is quite diverse (Knutson, et al., 1992) central of vesicular zones ranges from about $5 \%$ to $22 \%$, permeability measurements on basalt core suge $z o n e s$
thanges less than $1 \%$ porosity can be very poorly interconnected or conversely micro-fractures. However, field injection and thace rock mass permeability. Horizontal fractures are the principal cause of the large scale rave ranged from 40 to 120 Darcies. In fractures are the principal cause of the
permeabilities measured at various different sites have ranged fontrill the matrix permeability of basalt is typically in the milli-Darcy range. 


\subsection{Fluid Flow in the Variably Saturated Zone}

The surficial sediments are primarily composed of eolian and alluvia! sand, loess, and lacustrine deposits (Barraclough, et al., 1976). Moisture movement through the sediments occurs at different rates depending on depth (Pittman, 1989; Davis and Pittman, 1990; McElroy and Hubbell, 1990). For example, in the upper 0.1 to $1 \mathrm{~m}$ of sediments, moisture movement is very dynamic and responds quickly to precipitation events as well as to periods of evaporation. Below this dynamic zone is a zone where the patterns of moisture movement are more gradual. At greater depth, changes in moisture movement are very small so that the moisture profile appears to be at steady-state.

Moisture movement occurs as a result of liquid and vapor phase flow (Hillel, 1971; Campbell, 1985). However, the vapor phase component is generally negligibly small. Liquid phase flow occurs as a result of capillary and gravity forces. Rates of liquid flow are functions of the: (1) moisture flux at the surface, (2) plant uptake, and (3) moisture retention and unsaturated hydraulic conductivity properties (McElroy, 1990; Kaminsky, 1991) of the surficial sediments. These flow phenomena in porous materials are reasonably well understood and described by Darcian flow theory.

In the case of the basalt strata, the physics of partially saturated flow are not well understood or defined. Although by analogy, it is expected that partially saturated flow in the rock matrix occurs by the same physical processes that occur in the soil. Only limited data (Bishop, 1991) currently exist on the retention and unsaturated hydraulic conductivity properties of basalt. The nature of the unsaturated flow properties of discrete fractures are presently unknown. Available theoretical work (Rassmussen, et al., 1987) suggests that fractures play a minimal role until the medium becomes fully saturated.

For the purposes of flow modeling, partially saturated flow in the vadose zone is conceptualized in terms of the following assumptions:

o the moisture flux at the surface is known and no plant uptake occurs,

o the hydraulic properties of the surficial sediments, interbeds, and basalt strata are homogeneous and anisotropic,

o moisture movement occurs as liquid phase transport only,

o the moisture retention (i.e., characteristic curve) properties of the sediments and basalt are non-hysteretic,

o Darcy's law for unsaturated flow is applicable to the fractured-porous basalt strata. In general, the above idealization is reasonable and applicable to conditions at the INEL. The last assumption, however, requires validation with laboratory and/or field data. 


\subsection{Fluid Flow in a Free Surface Aquifer}

Dynamics of groundwater in a basalt geology are, to a large degree, controlled by the layered nature of the lava flow's. In general, the top and bottom vesicular zones determine the rates and directions of horizontal groundwater flow because of their higher permeability. Flow along individual flow tops and bottoms are often hydraulically interconnected by vertical fractures through the central zone.

At relatively large scales (i.e., 100's of m/sters to kilometers), groundwater flow in the fractured-porous basalt geology can be modeled using the so-called "equivalent porous media" (EPM) approximation. This approximation is based on the idea that the large rock volume contains a sufficient number of fractures to exhibit an average rock mass permeability. Snow (1969) and Long, et al. (1982) have proposed theoretical criteria for judging the applicability of the EPM approximation.

Based on the aspects outlined above, groundwater flow in the saturated zone is conceptualized in terms of the following characteristics:

o the hydrostratigraphic units in the basalt geology are laterally extensive, continuous, and characterized as anisotropic,

o the flow system is unconfined with predominantly horizontal flow (i.e., Dupuit-Forchheimer approximation', and

o the large scale flow is described as Darcian flow in an equivalent porous medium, Past groundwater modeling studies at the INEL have used this type of conceptualization with considerable success. Robertson (1974), and more recently, Arnett et al. (1990) have modeled various contaminant plumes in the Snake River Plain aquifer and obtained good comparisons with field measurements.

\subsection{Heat Transport in the Soil}

Soil temperature is an important environmental variable because of its effects on the physical and chemical properties of contaminants. Heat transfer in the vadose zone occurs as a result of atmospheric heating and cooling at the soil surface. Principal modes of this surface heat transfer include: (1) long and short wave radiation, (2) evaporation, and (3) convection. Data for the RWMC (Pittman, 1989; Davis and Pittman, 1990) show that soil temperatures vary in a harmonic fashion over an annual cycle. These variations penetrate to a depth of about $5 \mathrm{~m}(16 \mathrm{ft})$. 
Therrnal energy moves through the vadose zone by the processes of conduction and advection. The advestive component, however, is negligibly small because of the low velocity of the pore-water movement. Available data indicates that thermal properties of the surficial sediments are relatively similar to those of basalt. For example, the thermal diffusivity of the sediments is estimated to be about $4.3 \times 10^{-3} \mathrm{~cm}^{2} / \mathrm{s}$, whereas, that of basalt is about $7.5 \times 10^{-3} \mathrm{~cm}^{2} / \mathrm{s}$. Because the mechanism of heat transfer in soil is relatively simple and the thermal properties are fairly uniform, soil temperature can be accurately predicted with a numerical model of heat conduction.

Based on the aspects described above, heat transport in the surficial sediments and basalt is conceptualized in terms of the following:

o heat transport occurs by pure conduction only,

o heat fiux variation at the surface drives heat transport, and

o the earth materials are characterized as porous media with homogeneous thermal properties.

The appropriateness of this conceptual representation has bean demonstrated by the authors through model applications and comparisons to available field data (Pittman, 1989). 


\subsection{MATHEMATICAL MODELS AND ASSUMPTIONS}

\subsection{Introduction}

To provide a general predictive tool for analysis of waste disposal sites, the FLASH computer code has been written to solve three general equations: (1) Richards' equations for variably saturated flow in the vadose zone, (2) the Dupuit-Forchheimer equation for saturated groundwater flow in an unconfined aquifer, and (3) the conduction heat transfer equation. The computer code is written to solve these equations in two-dimensions for transient or steady-state flow conditions.

\subsection{Fiuid Flow Equation for the Variably Saturated Zone}

The mathematical model for variably saturated flow in the vadose zone is based on the continuity equation for conservation of mass and Richards' extension of Darcy's law for unsaturated flow. The combination of these two equations produces the general governing equation for fluid flow in an unsaturated soil. This equation, modified to consider simultaneous saturated and unsaturated conditions, is expressed in the head-based form as:

$$
\left[S_{s} \frac{\theta}{\theta_{s}}+C(\psi)\right] \frac{\partial \psi}{\partial t}=\nabla \cdot[\bar{K}(\psi)(\nabla \psi+k)]
$$

where $\psi$ is the pressure head $(\mathrm{cm}), S_{s}$ is the specific storage $(1 / \mathrm{cm}), \theta$ and $\theta_{s}$ are the volumetric moisture content and saturated moisture content (i.e., porosity), $\bar{K}(\psi)$ is the unsaturated hydraulic conductivity tensor $(\mathrm{cm} / \mathrm{s})$, and $k$ is the unit vector in the vertical direction (positive upwards).

The two-dimensional, component form of the governing equation is

$$
\left[S_{s} \frac{\theta}{\theta_{s}}+C(\psi)\right] \frac{\partial \psi}{\partial t}-\frac{\partial}{\partial x}\left(K_{x}(\psi) \frac{\partial \psi}{\partial x}\right)+\frac{\partial}{\partial z}\left[K_{z}(\psi)\left(\frac{\partial \psi}{\partial z}+1\right)\right]
$$

The ronlinear coefficient $C(\psi)$ is the specific moisture capacity $(1 / \mathrm{cm})$, is defined by

$$
C(\psi)=\frac{\partial \theta}{\partial \psi}
$$

which is the slope of the soil moisture characteristic curve. The above equation, in most applications, is strongly nonlinear. As described later, this equation is solved iteratively using either a Picard or Newton iteration technique.

Note that for postive pressure heads, $\psi>0, \theta=\theta_{s}, K(\psi)-K_{s}$, and $C(\psi)=0$, reducing the variable saturate d equation (1) to that for confined flow: 


$$
S_{s} \frac{\partial \psi}{\partial t}-\nabla(K(\nabla \psi+\hat{k})
$$

Rigorous derivations of the variably saturated flow equation can be found in porous media textbooks (Hillel, 1971, Bear, 1972) and in the technical literature (Celia, et al., 1991). The mathematical theory, however, makes a number of basic assumptions:

o Low Reynolds number and single phase flow,

- Vapor phase flow is negligible,

o Non-hysteretic soil hydraulic characteristics,

o No internal sources or sinks of fluid,

o Fluid properties, i.e., density and viscosity, are independent of temperature, and

o Hydraulic properties of the porous continuum are volume averages.

In the model formulation implemented in the FLASH computer code, the further assumption is made that the conductivity tensor is aligned with the horizontal and vertical axes.

The variably saturated flow equation is solved with any combination of three types of boundary conditions

1. Dirichlet or specified pressure head

$\psi=\psi\left(x_{b}, z_{b}, t\right)$

2. Neumann or prescribed flux

$$
-K_{x}(\psi) \frac{\partial \psi}{\partial x} \hat{n}_{1}-K_{z}(\psi) \frac{\partial \psi}{\partial z} \hat{n}_{2}=q(t)
$$

3. Unit gradient or free drainage

$$
q_{f}=-K_{z}(\psi) k
$$

where $x_{b}$ and $y_{b}$ are the coordinates of the boundary with Dirichlet boundary conditions; $\hat{n}_{1}$ and $\hat{n}_{2}$ are the components of the outward pointing unit normal; $q_{f}$ is the fiuid flux.

\subsection{Fluid Flow Equations for a Free Surface Aquifer}

The mathematical model for areal groundwater flow in an unconfined aquifer originates from continuity and Darcy's law. By making the assumption that the groundwater flow is essentially horizontal, the applicable governing equation is the so-called Dupuit-Forchteimer equation (Freeze and Cherry, 1979). This well known governing equation is expressed in two-dimensional form as:

$$
S_{y} \frac{\partial h}{\partial t}=\frac{\partial}{\partial x}\left(K_{x} h \frac{\partial h}{\partial x}\right)+\frac{\partial}{\partial y}\left(K_{y} h \frac{\partial h}{\partial y}\right)
$$


where $h$ is the water level elevation $(\mathrm{cm}), S_{y}$ is the specific yield $(1 / \mathrm{cm}), K_{x}$ and $K_{y}$ are the saturated hydraulic conductivity $(\mathrm{cm} / \mathrm{s})$ in the $\mathrm{x}$ - and $\mathrm{y}$-directions.

This formulation is limited by the assumptions listed previously with the addition of three other fundiamental assumptions:

o Vertical components of groundwater flow are small,

o Fluid exchanges across the capillary fringe are negligible, and

o The bottom boundary of the aquifer is horizontal and $h$ represents the saturated thickness.

The Dupuit-Forchheimer equation for flow in an unconfined aquifer is mildly nonlinear. As implemented in the FLASH computer code, this formulation is solved iteratively using the Newton-Raphson method.

Boundary conditions used in solving the Dupuit-Forchheimer flow equation consist of two types:

1. Diricluet or specified pressure head

$h=h\left(x_{b}, z_{b}, t\right)$

2. Neumann or prescribed flux

$$
-T_{x} \frac{\partial h}{\partial x} \hat{n}_{1}-T_{z} \frac{\partial h}{\partial z} \hat{n}_{2}=q_{f}(t)
$$

where $T_{x}$ and $T_{y}$ are the transmissivities; $q_{f}$ is the fluid flux; all other quantities are as previo'isly defined.

\subsection{Heat Transport Equation for the Vadose Zone}

The principle of energy conservation together with Fourier's law provides the basis for the mathematical model of heat transport in the vadose zone. The baiance of thermal energy is expressed as governing equation of the form

$$
S_{1} \frac{\partial T}{\partial t}=\frac{\partial}{\partial x}\left(D, \frac{\partial T}{\partial x}\right)+\frac{\partial}{\partial y}\left(D, \frac{\partial T}{\partial y}\right)
$$

where $T$ is the temperature $\left({ }^{\circ} C\right), S$ and $D_{t}$ are the average volumetric hea apacity $\left(\mathrm{cal} / \mathrm{cm}^{3}-{ }^{\circ} \mathrm{C}\right.$ ) and thermal conductivity $\left(\mathrm{cal} / \mathrm{s}-\mathrm{cm}-{ }^{\circ} \mathrm{C}\right)$. The average thermal properties are computed as a weighted average of the properties of the soil and water according to the formulas:

$$
S_{t}=\rho_{f} c_{f} \theta+(1-\theta) \rho_{s} c_{s}
$$




$$
D_{t}=\theta D_{f}+(1-\theta) D_{s}
$$

where $\rho_{f}$ and $\rho_{s}$ are the densities of the fluid and soil, $c_{f}$ and $c_{s}$ are the specific heat capacities of the fluid and soil, $D_{f}$ and $D_{s}$ are thermal conductivities of the fluid and soil.

The applicability of this formulation is constrained by the following set of assumptions:

o The fluid and soil are in local thermodynamic equilibrium,

o Convective heat transport is small compared to transport by conduction.

o Thermal properties of the fluid are independent of temperature,

o Thermal properties of the soil are independent of moisture content,

Because the heat transport equation is independent of moisture content, it can be solved separately form the variably saturated flow equation.

Two types of boundary conditions apply to the heat transport equation. These boundary conditions are:

1. Dirichlet or specified temperature

$T-T\left(x_{b}, z_{b}\right)$

2. Neumann or prescribed flux

$$
-D_{1} \frac{\partial T}{\partial x} \hat{n}_{1}-D_{1} \frac{\partial T}{\partial z} \hat{n}_{2}=q_{h}
$$

where $q_{h}$ is the heat flux; all other quantities are as previously defined. 


\subsection{FINITE ELEMENT FORMULATION}

A general finite element solution approach was developed to solve the partial differential equations for fluid flow and heat transport, described in the previous section. The finite element approach was selected because it provides a computational capability that easily accommodates the complex and variable geometry of hydrogeologic features. This section describes the basic computational approach, numerical techniques and aspects of computer implementation.

\subsection{Computational Approach}

The finite element approach is an integral based method for solving linear and nonlinear partial differential equations on computational mesh composed of quadrilateral, triangular and/or linear elements. As implemented in the FLASH computer code, these elements may have straight or curved sides. These computational elements are illustrated in Figure 3.

$\mathbf{z}$
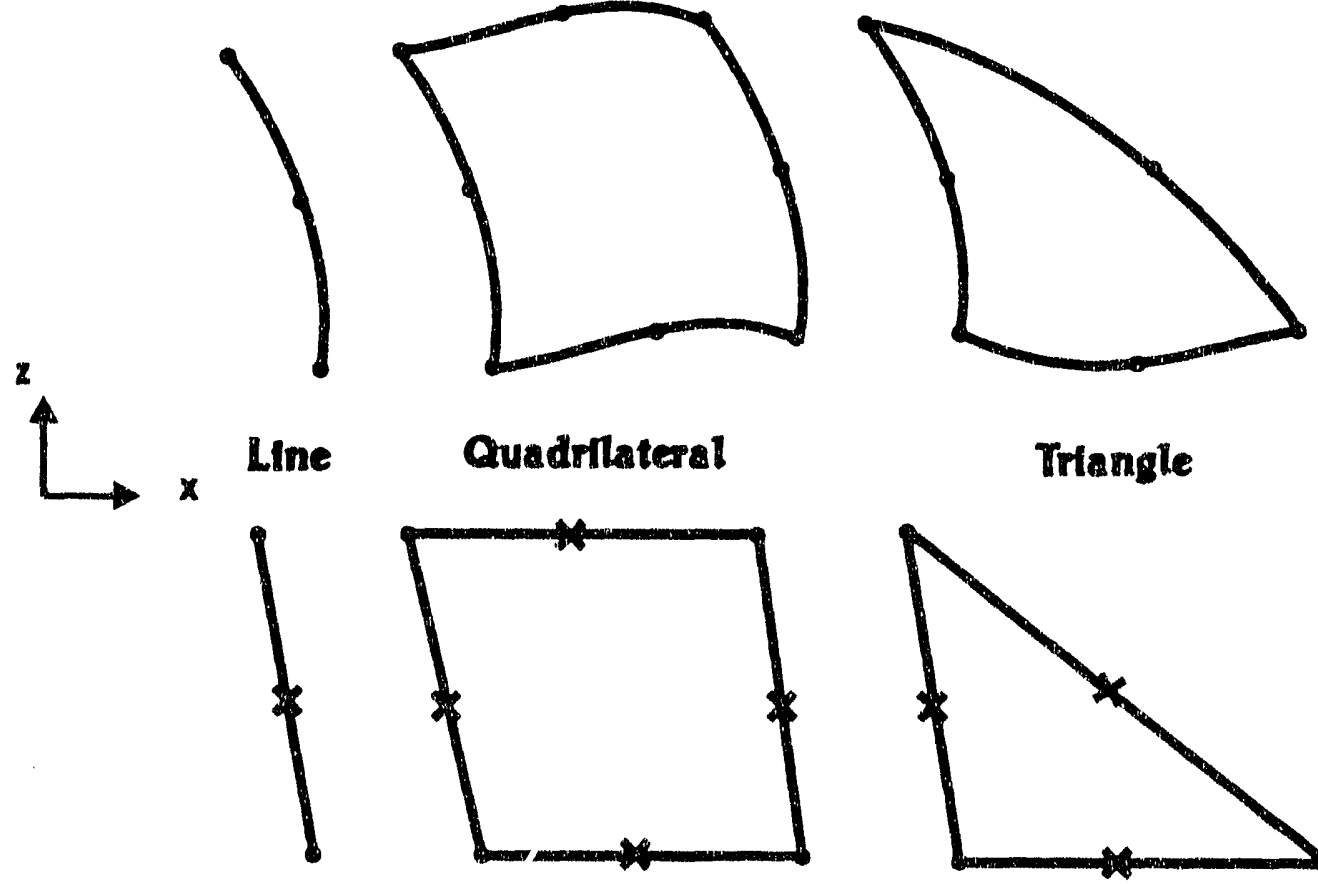

leoparametric

Triangle

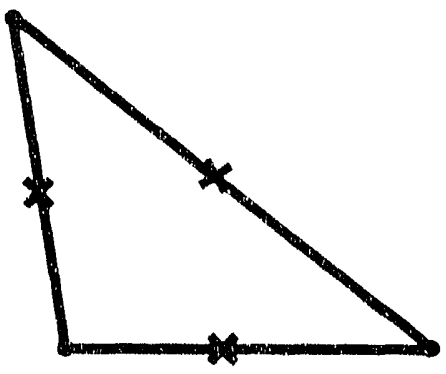

Linear

Figure 3. Types of Finite Elements used in Constructing a Computational Mesh 


\subsection{Galerkin Weak Statement}

A general finite element algorithm for the fluid flow and heat conduction equations was developed by applying the Galerkin method of weighted residuals (Baker, 1983). The fundamental concept is to form a functional $\chi$ as the integral of the product of the residual error $\varepsilon$ and a set of weighting functions $\omega_{j}$. The Galerkin functional is

$$
\chi=\int_{d} \varepsilon \omega_{j} d \bar{x}
$$

where $\mathfrak{R}$ is the domain of interest, $\varepsilon$ is formed from the governing equations, and $\bar{x}$ represents the generalized spatial coordinates $(x, y, z)$. Baca, et al. (1984) have shown that a direct superposition approach can be used to construct a functional equation that is applicable to flow and transport in a "fractured-porous" media.

Mathematically, the Galerkin weak statement for fractured-porous media $\chi_{f p}$ is derived from

$$
\chi_{f p}=\int_{Q_{c}} \varepsilon^{c} \omega_{j} d R+\int_{d_{d}} \varepsilon^{d} \omega_{j} d l
$$

where $\varepsilon^{c}$ and $\varepsilon^{d}$ are the residual error terms for the continuum domain $\Omega_{c}$ and discrete domain $\Omega_{d}$, respectively.

As in standard finite element procedure, the weak statement will be partitioned into subdomains or elements so that

$$
\chi_{f p}=\chi_{f p, 1}+\chi_{f p, 2}+\chi_{f p, 3}+\ldots+\chi_{f p, M}=\sum_{i=1}^{M} \chi_{f p, i}
$$

where $M$ is the total number of elements. Setting $\chi_{f p}=0$ imposes a requirement of orthogonality so that the weak statement becomes an error distribution principle (Collatz, 1960 ) by which the residual $\varepsilon$ is minimized over the domain $\Re=\Omega_{c} \cup \Omega_{d}$.

In this superposition approach, the continuum domain is represented by a mesh of two-dimensional, isoparametric, finite elements (eg., quadrilaterals and/or triangles) whereas, the discrete domain is represented by a network of line elements. The computational mesh used in this approach is the same as any standard finite element mesh with the exception that the line elements are superimposed along the boundaries of the two-dimensional elements, see Figure 4. Because the two types of elements share the same nodes, continuity of flow and transfer of thermal energy between the two elements is automatically enforced. 


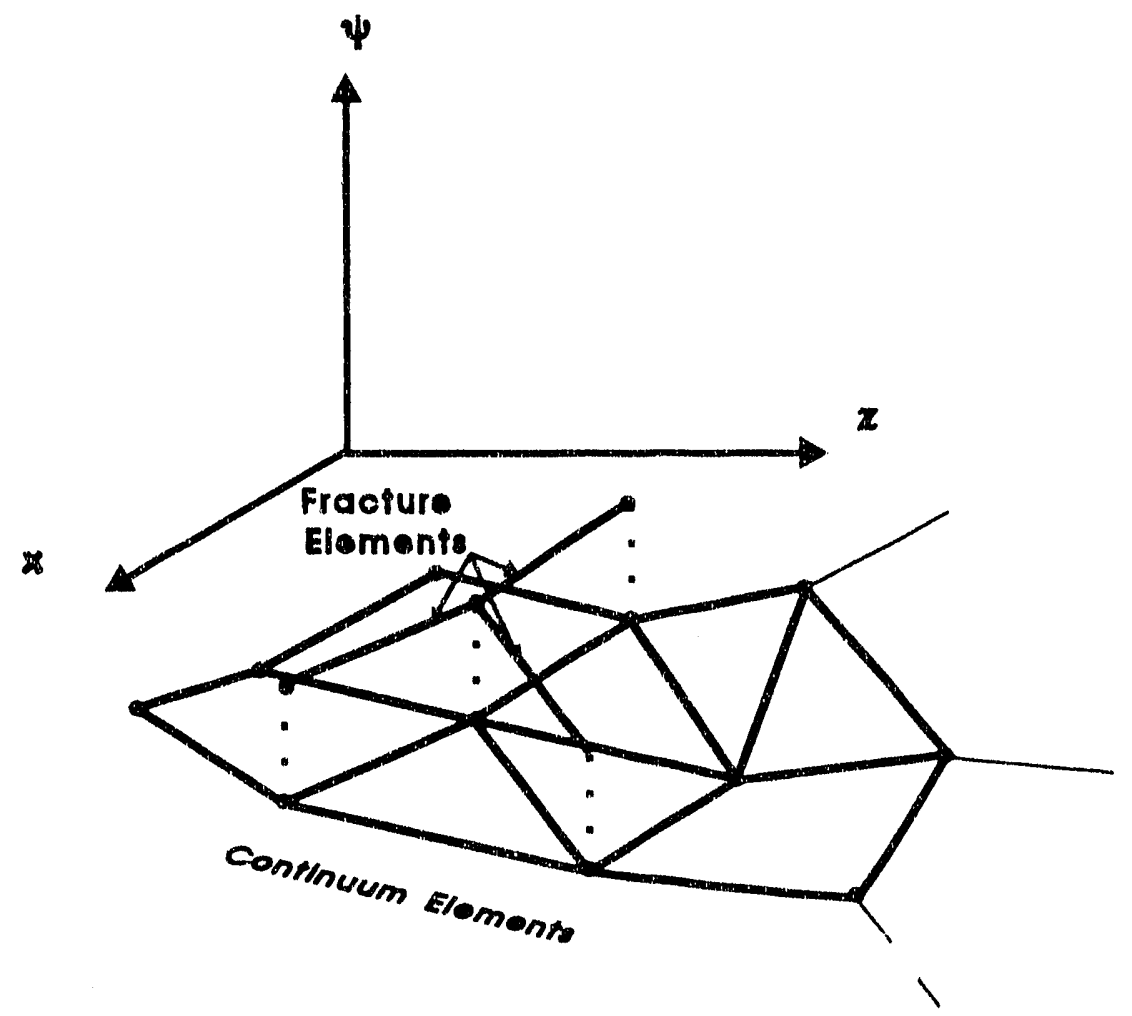

Figure 4. Superposition of Finite Elements

In developing the finite element algorithm for solution of the governing equations, a method referred to as the Taylor-Galerkin approach was used. This approach (Baca, et al., 1978 ) is an extension of the classical Galerkin method and is based on the use of a Taylor series expansion of the residual error. To demonstrate the approach, it is applied to the specific case of the heat conduction equation. In this particular case, the residual error is approximated by

$$
\varepsilon^{m+1}=\varepsilon^{m}+\frac{\partial \varepsilon^{m}}{\partial T} \Delta T
$$

Substituting this expression into equation (1) for an arbitrary element yields

$$
\chi_{c}=\int_{Q_{e}} \varepsilon^{m+1} \omega_{j} d \bar{x}-\int_{a_{e}}\left(\varepsilon^{m}+\frac{\partial \varepsilon}{\partial T} \Delta T\right) \omega_{j} d \bar{x}
$$

where $m$ is the iferation index and $\Delta T$ is the incremental change in temperature. Setting this equation to zero and rearranging the equation to place the unknowns on the left handside produces 


$$
\int_{a} \frac{\partial \varepsilon}{\partial T} \Delta T \omega_{j} d \bar{x}=-\int_{a_{c}} \varepsilon^{m} \omega_{j} d \bar{x}
$$

Once integrated, this equation leads to a set of 2!gebraic equations for the finite element of the form

$$
\left[J_{e}\right]\{\Delta T\}=\left\{R_{e}\right\}
$$

where $\left[J_{e}\right]$ is called the elemental Jacobian matrix, $\{\Delta T\}$ is the solution vector containing the incremental changes of temperature at each node point, and $\left\{R_{e}\right\}$ is called the elemental load vector and contains known information obtained from integration of $\left\{\varepsilon^{m}\right\}$ and the boundary conditions.

Specific expressions for $\left[J_{e}\right]$ and $\left\{R_{e}\right\}$ are obtained as follows. First, define the residual error in terms of the heat conduction equation:

$$
\varepsilon^{m}=S_{t} \frac{\partial T}{\partial t}-\nabla \cdot(D, \nabla T)
$$

The $\left\{R_{e}\right\}$ vector is thus expanded

$$
\left\{R_{e}\right\}=-\int_{a} \omega_{j}\left[S_{t} \frac{\partial T}{\partial t}-\nabla \cdot(D, \nabla T)\right] d \bar{x}
$$

Applying the divergence theorem to the integral of the spatial derivative term

$$
\left\{R_{e}\right\}=-\int_{Q_{e}}\left[\omega_{j} S_{t} \frac{\partial T}{\partial t}+\nabla \omega_{j} \cdot D_{t} \nabla T\right] d \bar{x}+\int_{\partial \alpha_{e}} \omega_{j} D_{t} \nabla T \cdot \bar{n} d S
$$

where $\bar{n}$ is the outward pointing normal on the boundary defined by $\partial \Omega_{e}$. The quantity $D, \nabla T$ in the surface integral can be replaced by the heat flux $\bar{q}_{h}$ vector; thus, one can write

$$
\left\{R_{e}\right\}=-\int_{\sigma_{e}}\left[\omega_{j} S_{t} \frac{\partial T}{\partial t}+\nabla \omega_{j} \cdot D, \nabla T\right] d \bar{x}-\int_{d \alpha_{e}} \omega_{j} \bar{q}_{h} \cdot \bar{n} d S
$$

The expression for the Jacobian matrix is derived from equation (11) by differentiating with respect to temperature. Specifically,

$$
\left[J_{e}\right]=\int_{a_{e}}\left[\omega_{j} S_{t} \frac{\partial}{\partial T}\left(\frac{\partial T}{\partial t}\right)+\nabla \omega_{j} \cdot D_{t} \frac{\partial}{\partial T}(\nabla T)\right] d \bar{x}
$$


The surface integral term vanishes in the Jacobian because the heat flux is not temperature dependant. In the above expression, the derivative of the time-dependent term was approximated as follows:

$$
\frac{\partial}{\partial T}\left(\frac{\partial T^{n+1}}{\partial t}\right)=\frac{\partial}{\partial T}\left(\frac{\alpha}{\Delta t}\left(T^{n+1}-T^{n}\right)+(1-\alpha) \frac{\partial T^{n}}{\partial t}\right)=\frac{\alpha}{\Delta t}
$$

where $n$ is the time plane index, $\alpha$ is a weighting factor, and $\Delta /$ is the time-step. The formula in the parenthesis is derived in a subsequent section. The final form for the Jacobian matrix becomes:

$$
\left[J_{e}\right]=\int_{\sigma_{e}}\left[\omega_{j} S_{t} \frac{\alpha}{\Delta t} \omega_{i}+\nabla \omega_{j} \cdot D, \nabla \omega_{i}\right] d \bar{x}
$$

In equations (11) and (12), the temperature over the domain of the finite element was approximated by

$$
T(\bar{x}, t) \div \sum_{i=1}^{N} \omega_{i} T_{i}
$$

where $N$ is number of node points, $\omega_{i}$ is the set of basis functions and $T_{i}$ is the set of temperatures at the node points. The basis functions are selected to be the same as the weighting functions, as required by the Galerkin procedure. Integrating the Jacobian matrix and load vector by a Gauss-Legendre quadrature method produces the final elemental matrices.

Combining the elemental matrices (Burnett, 1987) for all the elements in the mesh produces a system of symmetric, sparse, and banded algebraic equations of the general form:

$$
[J]\{\Delta T\}=\{R\}
$$

where $[J]$ is the global Jacobian matrix, $\{\Delta T\}$ is the solution vector containing the incremental changes of temperature at all the node points, and $\{R\}$ is the global load vector. The solution of equation (16) is obtained by Gaussian elimination techniques (see section 4.6) and then used in the iteration formula:

$$
\{T\}^{m+1}=\{T\}^{m}+\{\Delta T\}
$$

Because the heat conduction equation is linear, only a single iteration of the above is required. 


\subsection{Newton Based Weak Statement}

An important characteristic of the governing partial differential equation for variably-saturated flow is its strongly nonlinear nature. Because of the nonlinearity, an iterative method is required to obtain numerical solutions. A weak statement for the nonlinear equation was developed from the Taylor-Galerkin weak statement. This approach produces the iteration formula for residual error:

$$
\varepsilon^{m+1}=\varepsilon^{m}+\frac{\partial \varepsilon^{m}}{\partial \psi} \Delta \psi
$$

Inserting this expression into the general equation for the functional (sec section 4.2) gives:

$$
\int_{a}\left(\varepsilon^{m}+\frac{\partial \varepsilon^{m}}{\partial \psi} \Delta \psi\right) \omega_{j} d \bar{x}=0
$$

Because the first term in the functional represents known quantities the equation can be rearranged

$$
\int\left(\frac{\partial \varepsilon^{m}}{\partial \psi} \Delta \psi\right) \omega_{j} d \bar{x}=-\int_{b} \varepsilon^{n} \omega_{j} d \bar{x}
$$

This equation, once expanded using the finite element procedure (Burnett, 1987), leads to a system of unsymmetric, sparse, and banded aigebraic equations of the form

$$
[J]\{\Delta \psi\}=\{R\}
$$

where $[J]$ is the global Jacobian matrix, $\{\Delta \psi\}$ is the sol tion vector containing the incremental changes of pressure head at each node, and $\{R\}$ is the global load vector. The solution of equation (21) is used in the iteration formula:

$$
\{\psi\}^{m+1}=\{\psi\}^{m}+\{\Delta \psi\}
$$

Using $\{\psi\}^{m+1}$, the matrices in equation (4) are updated and then solved repeatedly along with equation (22) until convergence is achieved, i.e., $|\Delta \psi|<\varepsilon$.

Specific expressions for the elemental matrices, $\left[J_{e}\right]$ and $\left\{R_{e}\right\}$, are obtained as follows. The residual error for the flow equation is:

$$
\varepsilon^{m}-\left(S_{s} \frac{\theta}{\theta_{s}}+\frac{\partial \theta}{\partial \psi}\right) \frac{\partial \psi}{\partial t}-\nabla \cdot K(\nabla \psi+\hat{k})
$$

The load vector is thus 


$$
\begin{gathered}
\left\{R_{e}\right\}=-\int_{d}\left\{\left(S_{s} \frac{\theta}{\theta_{s}}+\frac{\partial \theta}{\partial \psi}\right) \frac{\partial \psi}{\partial t} \omega_{j}+\nabla \omega_{j} \cdot K(\nabla \psi+k)\right\} d \bar{x} \\
-\int_{\delta a} \omega_{j} \bar{q}_{j} \cdot \vec{n} d S
\end{gathered}
$$

where $\bar{q}_{f}$ in the surface integral is the Darcy flux vector. The Jacobian matrix is given by

$$
\left[J_{e}\right]=\int\left\{\left[\left(S_{s} \frac{\theta}{\theta_{s}}+\frac{\partial \theta}{\partial \psi}\right) \frac{\alpha}{\Delta t} \omega_{i}+\frac{\partial^{2} \theta}{\partial \psi^{2}} \frac{\partial \psi}{\partial t}\right] \omega_{j}+\nabla \omega_{j} \cdot\left(K \nabla \omega_{i}+\frac{\partial K}{\partial \psi}(\nabla \psi+k)\right)\right\} d \bar{x}
$$

In both equations (24) and (25), the divergence theorem was applied to reduce the second order derivative terms. Also, the derivative of the time-dependent term was approximated by

$$
\frac{\partial}{\partial \psi}\left(\frac{\partial \psi^{n+1}}{\partial t}\right)=\frac{\dot{\partial}}{\partial \psi}\left(\frac{\alpha}{\Delta t}\left(\psi^{n+1}-\psi^{n}\right)+(1-\alpha) \frac{\partial \psi^{n}}{\partial t}\right)-\frac{\alpha}{\Delta t}
$$

where $n$ is the time plane index, $\alpha$ is a weighting factor, and $\Delta l$ is the time-step.

\subsection{Picard Based Weak Statement}

Development of a Picard based finite element solution for the fluid flow equation requires generation of a weak statcment. The weak statement is formed as the integral of the product of the residual error and a set of weighting functions. An expression for the residual error is derived from the governing partial differential equation for variably saturated flow.

As described by Celia, et al. (1990), numerical colutions of the mixed-form of Richards' equation yields results with excellent mass conservation properties. This mixed-form of ihe governing equation is derived directly from the following form of the flow equation:

$$
\left(S_{s} \frac{\theta}{\theta_{s}}\right) \frac{\partial \psi}{\partial t}+\frac{\partial \theta}{\partial t}-\nabla \cdot K(\nabla \psi+k)
$$

where $\theta$ is the volumetric water content, $\theta_{s}$ is the saturated water content or porosity, $S_{s}$ is the specific storage coefficient and $k$ is the unit normal pointing up.

The mixed-form is derived by first approximating $\theta$ through the iteration space using a first order Taylor series:

$$
\theta^{m+1}=\theta^{m}+\left(\frac{d \theta}{d \psi}\right)^{m}\left(\psi^{m+1}-\psi^{m}\right)
$$

where $m$ is the iteration index. By differentiating both sides of this expression, one obtains 


$$
\frac{\partial \theta^{m+1}}{\partial t}=\frac{\partial \theta^{m}}{\partial t}+\left(\frac{d \theta}{d \psi}\right)^{m}\left(\frac{\partial \psi^{m+1}}{\partial t}-\frac{\partial \psi^{m}}{\partial t}\right)
$$

where all the above quantities are at the $n+1$ time level. Substituting this approximation into equation (1) and rearranging yields the desired mixed-form of Richards' equation

$$
\left(S_{s} \frac{\theta}{\theta_{s}}\right) \frac{\partial \psi^{m}}{\partial t}+C(\psi) \frac{\partial \delta}{\partial t}=\nabla \cdot K(\nabla \delta+\hat{k})+\nabla \cdot K \nabla \psi^{m}-\frac{\partial \theta^{m}}{\partial t}
$$

where $C(\psi)=\partial \theta / \partial \psi$ and $\delta-\psi^{m+1}-\psi^{m}$. In the above equation, the term $\partial \psi^{m} / \partial t$ is set to zero for unsaturated conditions, whereas, the terms $\delta$ and $\partial \theta^{m} / \partial t$ automatically go to zero as $\theta$ goes to $\theta_{s}$, i.e., saturation. Because the state variable is now $\delta$, the above mixed-form is raturally suited to a Picard type iteration method (Huyak orn and Pinder, 1983). For unsaturated conditions, the pressure head at the new iteration is computed from the iteration formula

$$
\psi^{m+1}-\psi^{m}+\delta
$$

The weak statement for the mixed-form of Richards' equation is formulated using the classical Galerkin approach (see section 4.2). The weak statement for an arbitrary element is written as

$$
\int_{\theta_{e}}\left\{\left(S_{s} \frac{\theta}{\theta_{s}}\right) \frac{\partial \psi^{m}}{\partial t}+C(\psi) \frac{\partial \delta}{\partial t}-\nabla \cdot K(\nabla \delta+\hat{k})-\nabla \cdot K \nabla \psi^{m}+\frac{\partial \theta^{m}}{\partial t}\right\} \omega_{j} d \bar{x}=0
$$

Applying the divergence theorem to reduce the second-order derivatives, the final form of the Picard based weak statement is obt.ined:

$$
\begin{aligned}
\int_{e}\left\{\omega _ { j } \left[\left(S_{s} \frac{\theta}{\theta_{s}}\right) \frac{\partial \psi^{m}}{\partial t}\right.\right. & \left.\left.+C(\psi) \frac{\partial \delta}{\partial t}+\frac{\partial \theta^{m}}{\partial t}\right]+\nabla \omega_{j} \cdot\left[K(\nabla \delta+\hat{k})+K \nabla \psi^{m}\right]\right\} d \bar{x} \\
& -\int_{\alpha_{c}} \omega_{j}\left[K(\nabla \delta+\hat{k})+K \nabla \psi^{m}\right] \cdot \vec{n} d S=0
\end{aligned}
$$

The first integral, in the above equation, applies to each finite element in the domain $\Omega_{e}$; whereas, the surface integral applies to that portion of the element boundary $\partial \Omega_{e}$ where fluid fluxes are specified. Application of the standard finite element procedure (Burnett, 1987) produces a matrix problem of the general form

$$
[A]\{\delta\}-\{R\}
$$


where $[A]$ and $\{R\}$ are the global coefficient matrix and load vector; the coefficient matrix is symmetric, sparse and banded. The matrix equation is solved by Gaussian elimination techniques (see section 4.6) for each iteration until convergence is achieved by equation (31), i.e., $|\delta|<\varepsilon$. Specific expressions for the elemental matrices are given by:

$$
\begin{gathered}
\left\{R_{e}\right\}=-\int_{\sigma_{e}}\left[\omega_{j}\left(S_{s} \frac{\theta}{\theta_{s}} \frac{\partial \psi^{m}}{\partial t}+\frac{\partial \theta^{m}}{\partial t}\right)+\nabla \omega_{j} \cdot K\left(\nabla \psi^{m}+\hat{k}\right)\right] d \bar{x}-\int_{d u_{e}} \omega_{j} \bar{q}_{f} \cdot \bar{n} d S \\
{\left[A_{e}\right]-\int_{\sigma_{e}}\left[\omega_{j} C(\psi) \frac{\alpha}{\Delta t} \omega_{i}+\nabla \omega_{j} \cdot K(\nabla \delta+\hat{k})\right] d \bar{x}}
\end{gathered}
$$

\subsection{Time Integration Scheme}

The Galerkin weak statement derived in the previous section utilized an approximation for the time derivatives of the pressure head, $\psi$, and the temperature, $T$. These quantities are approximated using a predictor-corrector method in conjunction with a Hermitian polynomial. This approach has been found to be significantly faster than the standard, weighted finite-difference method (Burnett, 1987).

\subsubsection{Predictor-Corrector Algorithm}

For simplicity, a simple two-step predictor-corrector algorithm was adopted. The algorithm uses an Euler predictor with a modified Euler corrector (Gerald and Wheatley, 1984). The predictor formula is a simple Euler method given by:

$$
\phi_{p}^{n+1}=\phi^{n}+\Delta t \frac{d \phi^{n}}{d t}
$$

where the state variable $\phi$, represents either pressure head $\psi$ or temperature $T$. The above predictor formula has a global error of $\operatorname{order} O(\Delta t)$. The corrector formula is the modified Euler approximation and expressed as

$$
\phi_{c}^{n+1}=\phi^{n}+\frac{\Delta t}{2}\left\{\frac{d \phi_{p}^{n+1}}{d t}+\frac{d \phi^{n}}{d t}\right\}
$$

which has a global error of $O\left(\Delta t^{2}\right)$. The calculation of $\phi_{c}$ is followed by a smoothing step which is based on the formula

$$
\phi^{n+1}=(1-\omega) \phi_{c}^{n+1}+\omega \phi^{n}
$$

where $\omega$ is a weighting factor. A fixed value of 0.5 is set in the computer code. 


\subsubsection{Derivation of Approximating Formula}

The time derivatives appearing in the previous predictor-corrector formulas are computed using an approximating Hermitian polynomial. The approximation formula was derived by first assuming an expression for the state variable as an explicit function of time. Specifically, the function is given by

$$
\phi^{n+1}-\phi^{n}+a t+b t^{\alpha}
$$

for any point in space. The terms $a, b$ and $\alpha$ are constants; $t$ is the independent variable of time. It follows that the time derivative at the $n+1$ time plane is then:

$$
\frac{d \phi^{n+1}}{d t}=a+a b t^{\alpha-1}
$$

An expression for the constant $b$ can be obtained from equation (40), namely

$$
b=\frac{1}{t^{a-1}}\left\{\frac{\phi^{n+1}-\phi^{n}}{t}-a\right\}
$$

The constant $a$ is determined from equation (41) by setting $t=0$. The result is the expression

$$
a=\frac{d \phi^{n}}{d t}
$$

Substituting the above expressions into equation (41) and replacing $t$ with $\Delta t$, the following approximation formula is obtained.

$$
\frac{d \phi^{n+1}}{d t} \frac{\alpha}{\Delta t}\left(\phi^{n+1}-\phi^{n}\right)+(1-\alpha) \frac{d \phi^{n}}{d t}
$$

This formula is a simple Hermitian polynomial (Strang and Fix, 1973). For $\alpha$ equal to 1 , the approximation reduces to a first-order backward difference. Similarly, for $\alpha$ equal to 2 , the equation yields a second order approximation that is equivalent to the Crank-Nicolson approximation. In most applications, a value of $\alpha$ between 1.6 and 1.8 generally provides the rnost accurate results.

\subsubsection{Automatic Time-Stepping}

For the purpose of user convemience and overall computational efficiency, an automatic time-stepping algorithm is implemented in the computer code. This feature is particularly useful when simulating partially saturated flow in relatively dry soils. The algorithm automatically increases or decreases the timemstep to assure a stable and accurate solution. 
The strategy used in code varies the time-step in such a manner as to maintain a relatively uniform time truncation error. This accomplished by monitoring the values of max $|\Delta \psi|$ and/or $\max |\Delta T|$ and comparing them against limits specified by the user. The time-step amplification factor is selected on the basis of an intricate criteria which considers:

$o$ the maximum and minimum changes in the state variables,

o the number of iterations,

0 rate of convergence,

o number of previous step reductions (if any).

For cases where the maximum values are exceeded for any of the above parameters, the time-step is reduced by a factor ranging from as little as 0.9 to as much as 0.5 ; the code then recalculates the solution with the smaller time-step. The algorithm monitors and limits the number of sequential time step reductions. For the case where the parameters are less than the minimum limiting values, the time-step is increased by a factor as little as 1.01 to as much as 1.9 .

\subsection{Solution of Algebraic Equations}

The application of the Galerkin finite element method to the governing equations produces a large system of algebraic equations of the form

$$
[A]\{x\}-\{b\}
$$

The coefficient matrix $[A]$ is a banded, sparse matrix which contains the assembly of the elemental matrices for all finite elements in the mesh. The $\{x\}$ and $\{b\}$ vectors are the solution vector and load vector, respectively.

For the case of the Picard based weak statement, the finite element method produces a coefficient matrix that is banded and symmetric. In contrast, the Newton-Raphson based weak statement generates a banded but unsymmetric coefficient matrix. For either case, the system of equations are solved using a Gaussian elimination procedure without pivoting.

Two distinct algorithms are implemented in the computer code. The first method is a standard band solver algorithm that utilizes a skyline storage scheme (Tewarson, 1973). This solver is very fast but can be limited by the bandwidth of the $[A]$; the bandwidth is direct function of the node numbering. The second method is referred to as the frontal method (Hinton and Owen, 1977). This method, in general, is slower than the band solver but has the advantage that it is independent of bandwidth and requires much less storage. In the frontal method, the elimination process is carried out according to the element numbering. 
Algorithms for minimizing matrix bandwidth (Cuthill, 1972, Gibbs, et al., 1976) exist that use strategies for optimizing the node number ordering. Similarly, techniques for minimizing the front width are based on reordering of element numbers (King, 1970). For problems with very large matrices, these minimization techniques often produce significant reductions of simulation run times. 


\subsection{COMPUTATIONAL EXAMPLES}

A set of computational examples were selected and to demonstrate the general capability of the FLASH computer code. The examples serve to illustrate the application of the FLASH code to such simulation problems as modeling partially saturated flow, saturated-unsaturated flow, and conduction heat transfer. Examples for free surface flow are in preparation. The FLASH solutions to these computational examples are compared to analytical and bechmark numerical solutions. These input files for these computational examples are presented in Appendix 1.

\subsection{Partially Saturated Flow in a Dry Soil}

\subsubsection{Problem Statement}

In this first computational example, the difficult problem of modeling partially saturated flow in a relatively dry soil column is considered. The physical setting is a vertical soil-column, idealized as a homogeneous porous medium, see Figure 5. Initially, the soil is at a very low saturation level, i.e., large negative pressure head. A wetting front is produced by maintaining the top surface at a near saturated condition. Vertical movement of the wetting front occurs by the action of capillary and gravity forces. The objective of the simulation problem is to compute the soil-moisture profile at various times.

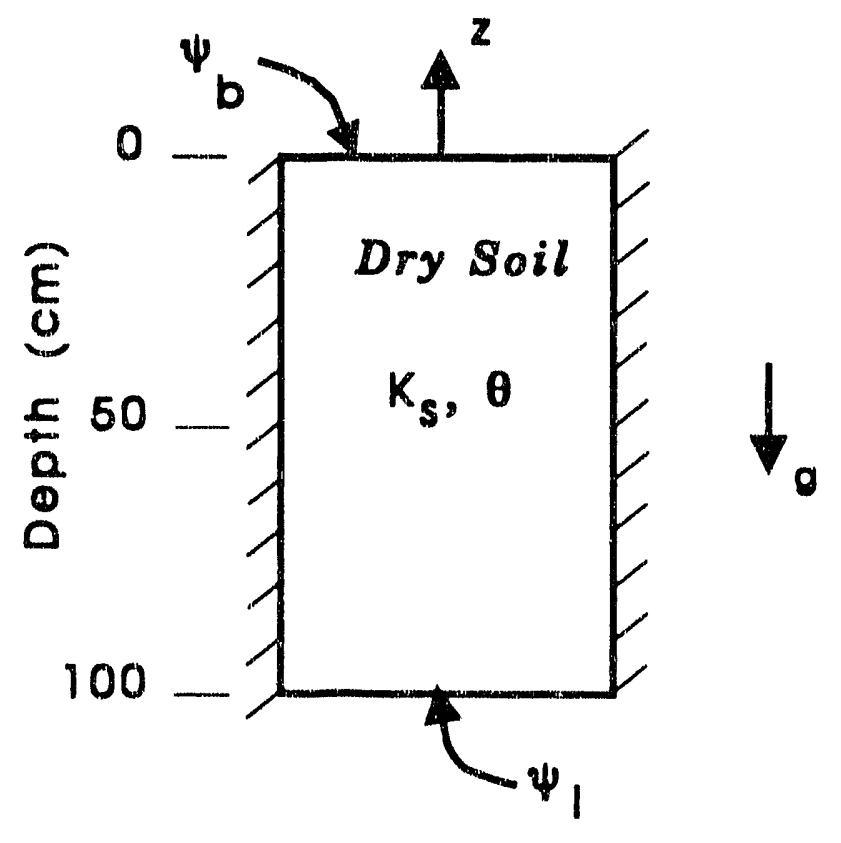

Figure 5. Domain and Boundary Conditions for Variably Saturated Flow Problem 
This particular computational example was originally used by Celia, et al. (1990) to test the stability and accuracy of various numerical techniques. Tr.example is an exceptionally good one because the flow problem is a strongly nonlinear and exhibits a ve ry sharp wetting front. These characteristics are typical of soil-moisture dynamics in arid site vadose zones such those at the INEL, Hanford and the Nevada Test Site.

One-dimensional flow in a partially-saturated porous medium is described by a nonlinear governing equation, known as Richards' equation, expressed as:

$$
\left.C(\psi) \frac{\partial \psi}{\partial t}=\frac{\partial}{\partial z}[K(\xi))\left(\frac{\partial \psi}{\partial z}+1\right)\right]
$$

where $\psi$ is the pressure head, $K(\psi)$ is the unsaturated hydraulic conductivity, $t$ is time, and $z$ is the distance along the vertical coordinate which is positive in the upward direction. The specific moisture capacity $C(\psi)$ is defined by $C(\psi)=\partial \theta / \partial \psi ; \theta$ is the volumetric moisture content. The applicable boundary conditions are

$$
\begin{gathered}
\psi(0, t)=\psi_{b} \\
\psi(-L, t)=\psi_{i}
\end{gathered}
$$

witere $L$ is the length of the soil column. As indicated above, the top boundary is fixed at a pressure head of $\psi_{b}$, whereas, the bottom boundary is held at the initial value $\psi_{i}$.

\subsubsection{Benchmark Numerical Solution}

Numerical solutions for this computation example are presented and discussed in Celia, et al. (1990) and Celia (1991). The model domain used by these authors consisted of a 100 $\mathrm{cm}$ vertical, soil column. A computational grid was used to represent the domain consisting of a column of grid blocks, each being $2.5 \mathrm{~cm}$ in length. Celia utilized the UNSAT1D computer code (Celia, 1991) to compute the pressure head and moisture content profiles at various times.

Hydraulic properties assigned to the idealized soil column were taken from data for the Jornada test site in New Mexico. These properties were represented using the van Genuchten formulas (van Genuchten, 1980) for the characteristic and unsaturated conductivity curves:

$$
\begin{gathered}
\theta(\psi)-\theta_{r}+\frac{\theta_{s}-\theta_{r}}{\left[1+(\alpha|\psi|)^{n}\right]^{m}} \\
K(\psi)=K_{s} \frac{\left\{1-(\alpha|\psi|)^{n-1}\left[1+(\alpha|\psi|)^{n}\right]^{-m}\right\}^{2}}{\left[1+(\alpha|\psi|)^{n}\right]^{n / 2}}
\end{gathered}
$$


where $\theta$ is the volumetric moisture content, $\theta_{r}$ is the residual moisture content, $\theta_{s}$ is the saturated water content or porosity, and the $\alpha, n$ and $m$ are fitting parameters. Specific values used in this computational example were $\alpha=0.0335, n=2 ., \theta_{s}=0.368$ and $\theta_{r}=0.102$. The fitting parameter $m$ is computed from $m-1-1 / n$. The saturated hydraulic conductivity, $K_{s}$, and specific storage coefficient, $S_{s}$, were $9.22 \times 10^{-3} \mathrm{~cm} / \mathrm{s}$ and $1.0 \times 10^{-5} \mathrm{~cm}^{-1}$, respectively. The initial and surface boundary pressure heads were set at $\psi_{i}=1000 \mathrm{~cm}$ and $\psi_{b}=-75 \mathrm{~cm}$, re pectively.

For the purposes of this computational example, the UNSAT1D code (Celia, 1991) was run to simulate the moisture movement for a 1 day simulation period. Pressure head and moisture content profiles at $t=0.5$ days and $t=1.0$ days were computed for use in making comparisons with results from the FLASH computer code. The UNSAT1D code was run using a fixed time-step $\Delta t=600 \mathrm{sec}$.

\subsubsection{Numerical Solution}

The FLASH computer code was setup to simulate this one-dimensional flow problem for a total simulation period of 1.0 day. A uniformly spaced, finite element mesh composed of 40 line elements and with a total of 81 nodes was used to represent the soil column. The FLASH code was run using the Picard iteration option, linear elements, and automatic time-stepping. As the simulation progressed, the time steps sizes varied from $600 \mathrm{sec}$ to 8000 sec. Solutions for each time converged in 3 to 5 iterations.

Pressure head and moisture content profiles computed with the FLASH code are compared with those obtained with the UNSAT1D code for three time plate: $t=1.5 \times 10^{4}$, $6.0 \times 10^{4}$ and $1.35 \times 10^{5} \mathrm{~s}$. The graphical comparisons are summarized in Figures 6 and 7. The comparison of numerical results show exceptionally good agreement at the first time plane. However, for the second and third time planes, the results indicate that the solutions differ slightly with regard to the front location. This is probably due to the different approaches used to account for the variation of hydraulic conductivity across the element.

In any case, it is clear from the graphical comparisons that both codes do an excellent job of capturing the sharp wetting front without introducing spurious oscillations. Computer execution times for this computational example were 20 seconds for the FLASH code and 1000 seconds for the UNSAT1D code. Both computer codes were run on a 386 personal computer. 


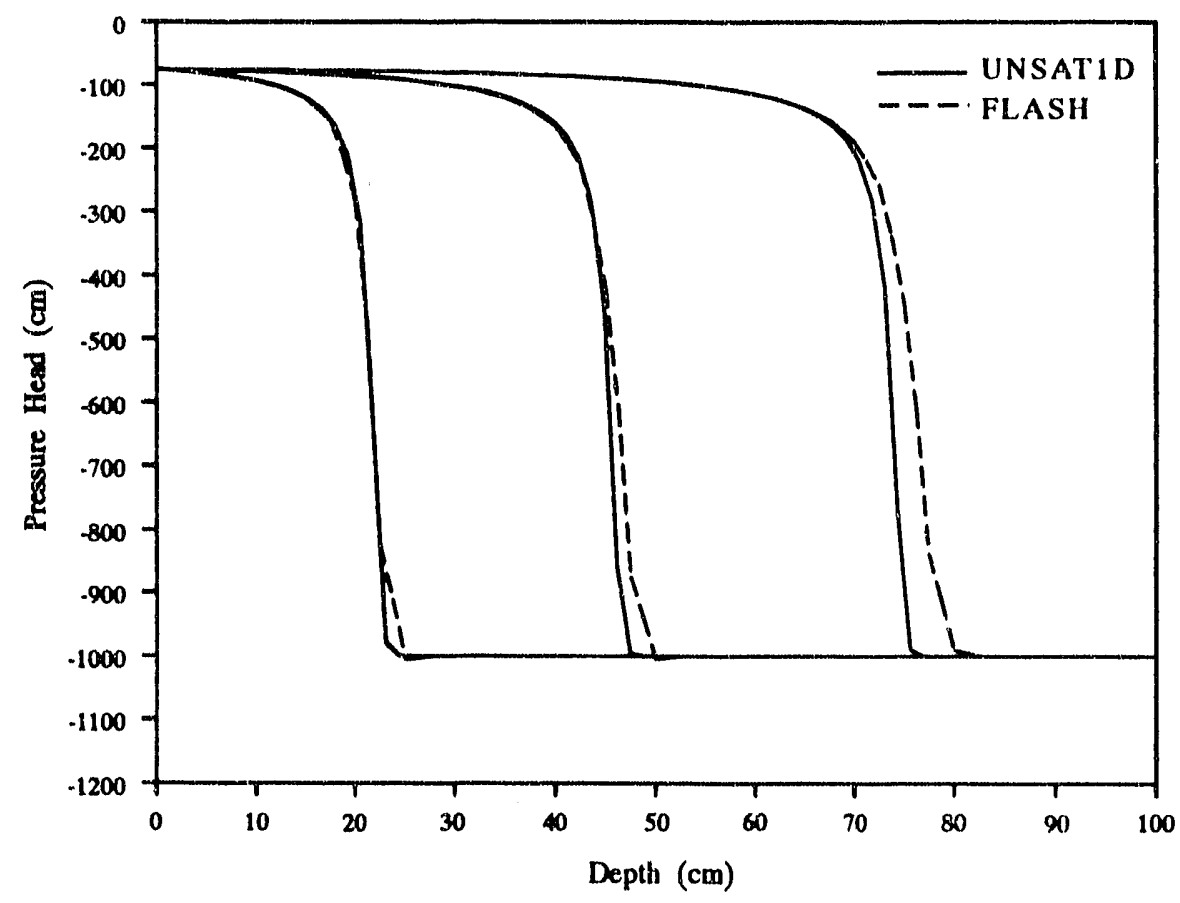

Figure 6. Comparison of Pressure Head Profiles computed with FLASH and UNSAT1D codes

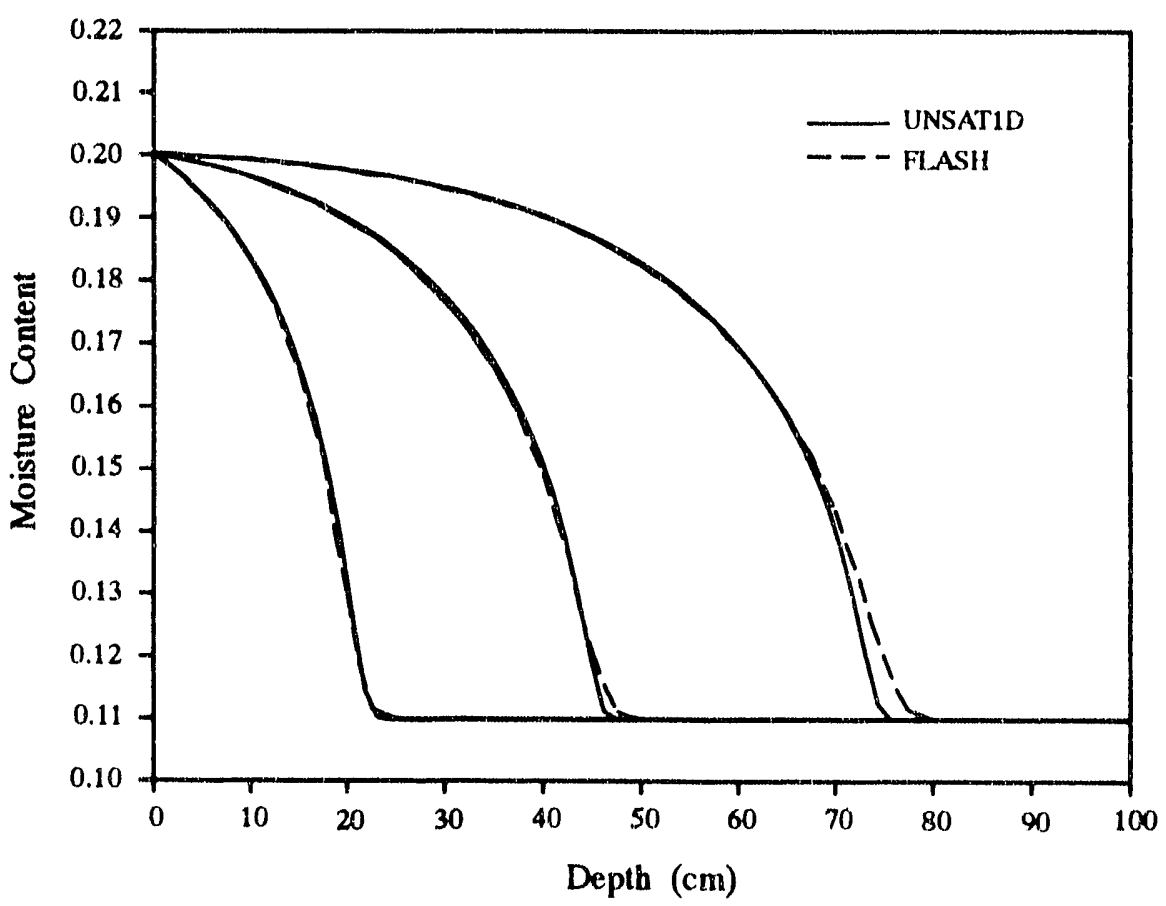

Figure 7. Comparison of Moisture Content Profiles computed with FLASH and UNSAT1D codes 


\subsection{Saturated-Unsaturated Flow in a Two-Dimensional Domain}

\subsubsection{Problem Statement}

The second computational example involves the modeling of two-dimensional flow in a system with both saturated and partially saturated flow regimes. The physical setting is conceptualized as a vertical cross-section with a shallow vadose zone and an unconfined aquifer, see Figure 8. Flow through the vadose zone is driven by a constant moisture flux at the surface. In the aquifer, a hydraulic gradient is maintained by fixed pressure head on the boundaries. The objective of this simulation problem is to compute the moisture content distribution throughout the domain.

This example, taken from Huyakorn, et al. (1989), has been used in previous computational testing of computer codes (Magnuson, et al., 1991). The example poses a good test case because of its nonlinear and linear behavior, large pressure variations and mixed boundary conditions. Many practical model applications exhibit these characteristics and conditions.

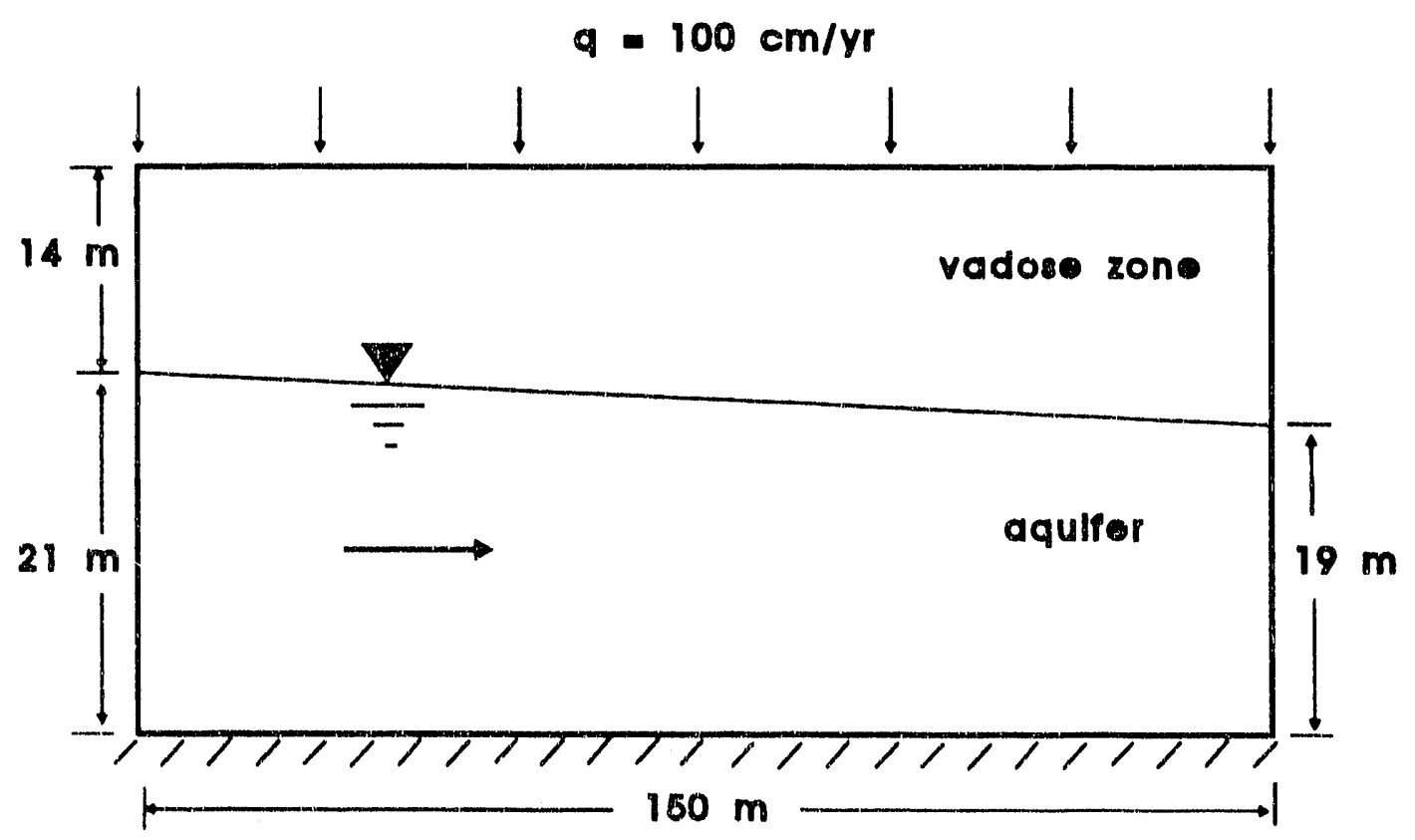

Figure 8. Domain and Boundary Conditions for

Saturated-Unsaturated Flow Problem 
Saturated-unsaturated flow in porous media is described by the nonlinear governing equation:

$$
\left[S_{s} \frac{\theta}{\theta_{s}}+C(\psi)\right] \frac{\partial \psi}{\partial t}=\frac{\partial}{\partial x} K(\psi) \frac{\partial \psi}{\partial x}+\frac{\partial}{\partial z} K(\psi)\left(\frac{\partial \psi}{\partial z}+1\right)
$$

where $S_{s}$ is the specific storage and $\theta_{s}$ is the saturated moisture content; all other parameters are as previously defined. The boundary conditions on the physical system are those used by Huyakorn, et al. (1989):

o Constant flux $q$ on the soil surface,

o No flow on the vertical boundaries of the vadose zone,

o Fixed pressure heads on vertical boundaries of the aquifer, and

o No flow on the bottom boundary.

The prescribed pressure heads on the boundary of the aquifer were based on height of the water column and were selected to produce flow from left to right.

\subsubsection{Benchmark Numerical Solution}

A number of independent numerical solutions are available in the literature for this computational example. The numerical solutions obtained by Magnuson, et al. (1990) with the PORFLO-3 code were selected for benchmark comparisons. For their numerical solutions, these authors used a finite difference grid consisting of 31 nodes in the horizontal direction and 27 nodes in the vertical direction. The grid spacing was uniform in the horizontal direction but was graded in the vertical direction.

Soil hydraulic properties assigned to the porous domain were taken from Huyakorn, et al., (1989). These authors utilized the analytic equations for the characteristics and hydraulic conductivity curves of the form:

$$
\begin{gathered}
\theta(\psi)=\theta_{r}+\frac{\left(\theta_{s}-\theta_{r}\right)}{\left[1+\left(\alpha|\psi|^{\beta}\right)\right]^{r}} \\
K(\psi)=K_{s}\left[\frac{\left(\theta-\theta_{r}\right)}{\left(\theta_{s}-\theta_{r}\right)}\right]^{\tau}
\end{gathered}
$$

where $\alpha, \beta, \gamma$ and $\tau$ are fitting parameters. Parameter values used in this example were taken from Magnuson, et al. (1990) and are listed below

$$
\begin{array}{ll}
\alpha=0.2 & \beta-2 . \\
\gamma=-1 & \tau=4
\end{array}
$$




$$
\theta_{s}=0.41 \quad \theta_{r}=0.25
$$

The saturated hydraulic conductivity was $K_{s}=2.378 \times 10^{.3} \mathrm{~cm} / \mathrm{s}$ and the surface moisture flux was $q=3.171 \times 10^{-6} \mathrm{~cm} / \mathrm{s}$.

The initial condition for pressure head in the saturated zone was chosen to create the water table at an average height of $18 \mathrm{~m}$ above the bottom boundary. In the vadose zone, the pressure heads were initially set to a uniform pressure of $-1000 \mathrm{~cm}$.

\subsubsection{Numerical Solution}

The FLASH computer code was set up to model the variably saturated flow problem using a time-marching approach to steady-state. The specific storage coefficient was arbitrarily set at a value of $S_{s}=0.01 \mathrm{~cm}^{-1}$ for use in the time-dependent computations. The code was run using the Picard iteration and linear elements, and automatic time stepping. A graded finite element mesh was generated and superimposed on the rectangular domain. The mesh consisted of 42 quadrilateral elements in the horizontal direction and 60 elements in the vertical direction.

The pressure head distribution computed with the Fl.A.SH code reached steady-state after a time period of 100 days. The pressure head solution along a centered plane was summarized in a profile plot and compared graphically with PORFLO-3 results similar to those published in Magnuson et al. (1990). The comparion of pressure head profiles showed gond agreement between the FLASH and PORFLO-3 results, see Figure 9. In addition, the moisture content profile along the same centered vertical plane is shown in Figure 10. 


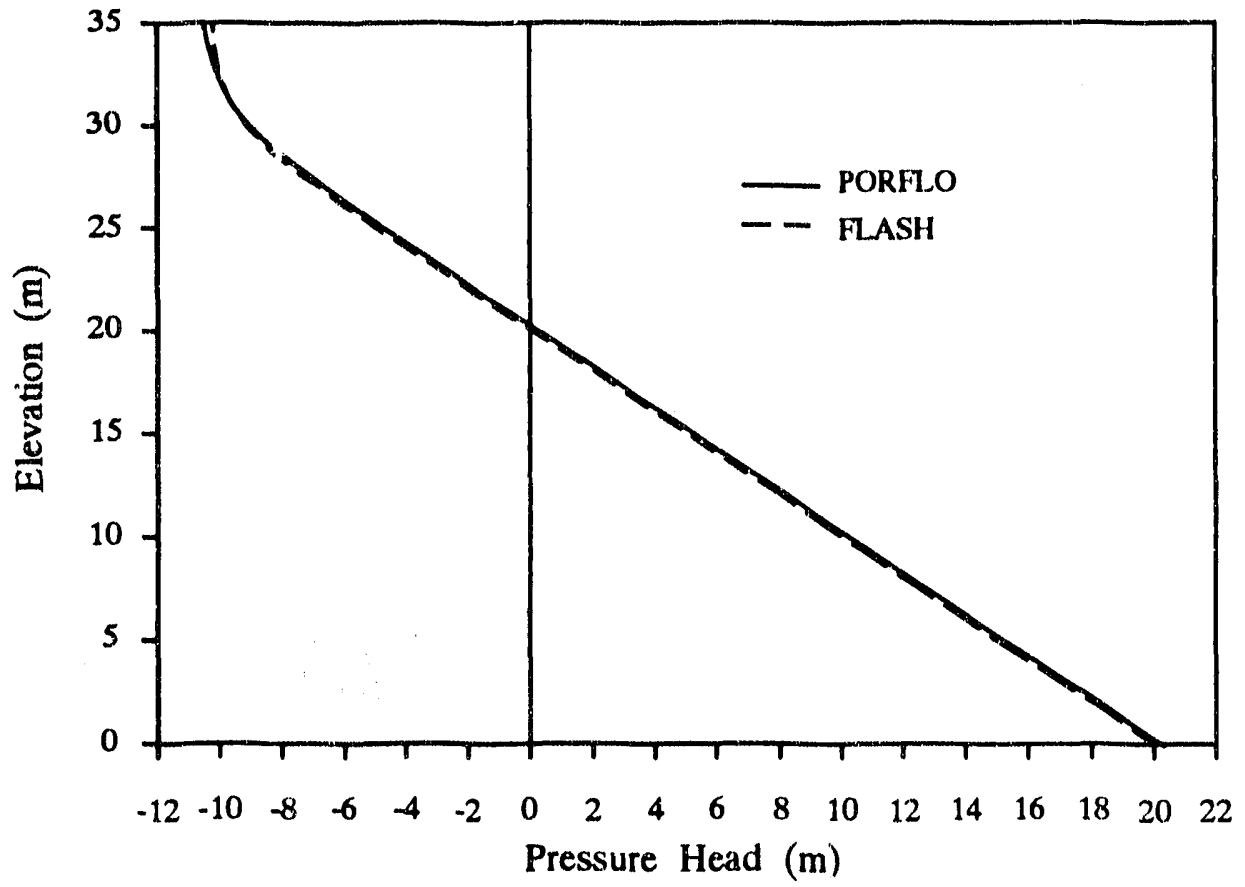

Figure 9. Comparison of Pressure Head Profiles computed with FLASH and PORFLO-3 codes

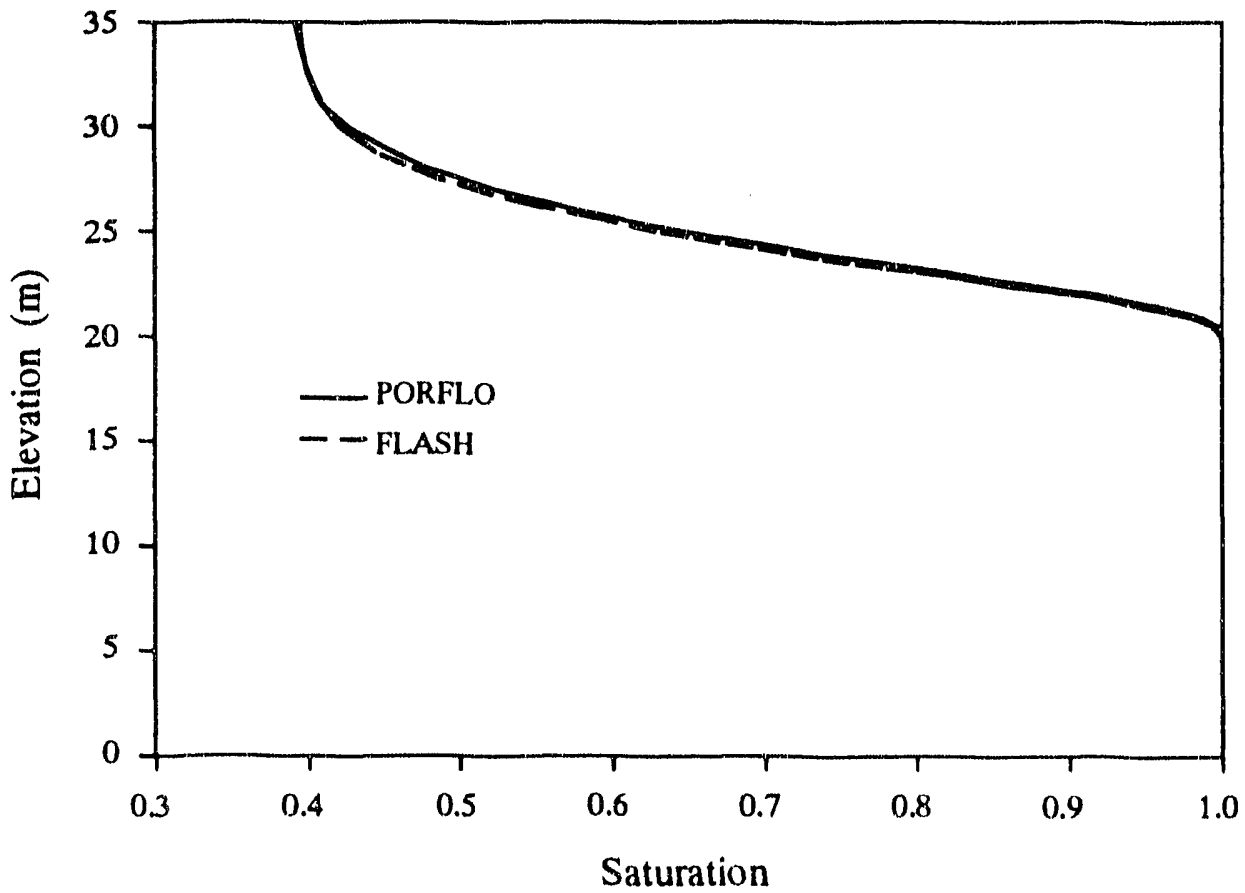

Figure 10. Comparison of Moisture Content Profiles computed with FLASH and PORFLO-3 codes 


\subsection{Heat Transport from a Buried Heat Source}

\subsubsection{Problem Statement}

This computational example considers the problem of modeling heat transfer from an infinitely long cylindrical heat source, buried in a homogeneous soil. For simplicity, the soil is assumed to have uniform thermal properties, moisture content, and to be in thermal equilibrium with the atmosphere. The heat source is buried at a depth $H$ and has a radius $R_{c}$, see Figure 11. Heat is transferred from the cylinder, through the soil, and to the soil surface at a steady-state rate. The objective of this computational test is to compute the temperature distribution in a localized soil region around the heat source.

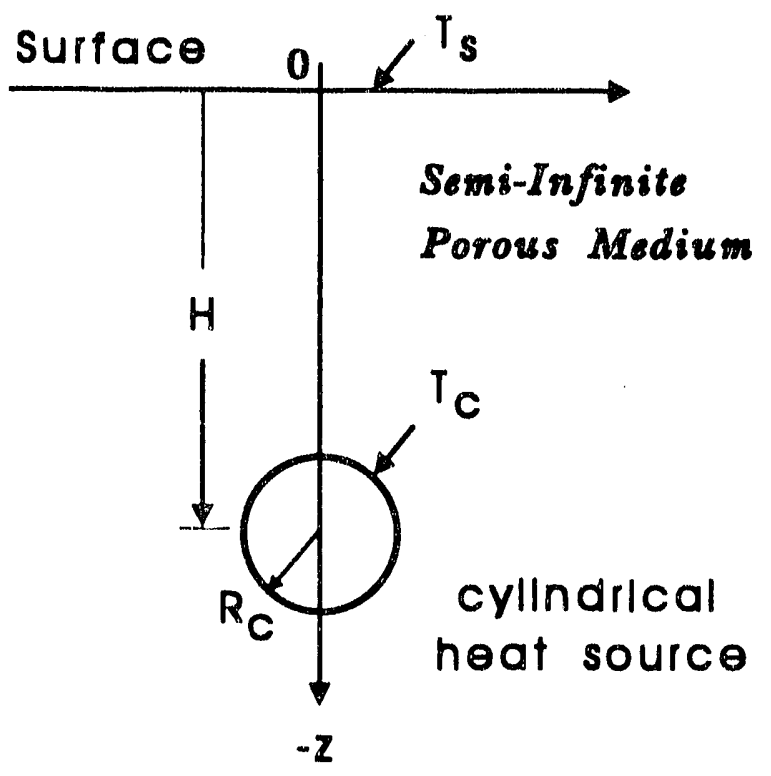

Figure 11. Domain and Boundary Conditions for

\section{Heat Transport Problem}

In terms of a boundary value problem, the heat transfer in the soil can be modeled in Cartesian coordinates using the governing equation

$$
K_{t} \frac{\partial^{2} T}{\partial x^{2}}+K_{t} \frac{\partial^{2} T}{\partial z^{2}}=0
$$

where $K_{1}$ is the thermal conductivity. The geometry of the problem has a plane of symmetry along the vertical axis which simplifies the boundary conditions. The boundary conditions are: 


$$
\begin{gathered}
\frac{\partial T(0, z)}{\partial x}=0 \\
T\left(x_{R_{c}}, z_{R_{c}}\right)=T_{c} \\
T(x, 0)=T_{s} \\
T(\infty, z)=\text { finite }
\end{gathered}
$$

Analytical and numerical solutions for this boundary were compared to illustrate the heat transport capability of the FLASH computer code.

\subsubsection{Analytical Solution}

The above heat transport problem has a closed-form analytical solution which is easily derived by first converting the governing equation to bipolar coordinates $\eta$ and $\psi$ (Arfken, 1970, pp. 97-102). The transformation to bipolar coordinates is achieved using

$$
\eta=\ln \left[\frac{x^{2}+(a-z)^{2}}{x^{2}+(-a-z)^{2}}\right] \quad \psi=\frac{2 a x}{x^{2}+z^{2}-a^{2}}
$$

where

$$
a=\left(H^{2}-R_{c}^{2}\right)^{1 / 2}
$$

Using the above expressions, the governing equation transforms to

$$
\frac{\partial^{2} T}{\partial \eta^{2}}=0
$$

with boundary conditions of

$$
T(0, \psi)=0 \quad T\left(\eta_{c}, \psi\right)=1
$$

which has the solution in the Cartesian space of

$$
T(x, z)=\frac{T_{c}}{2} \ln \left[\frac{x^{2}+(a-z)^{2}}{x^{2}+(-a-z)^{2}}\right] / \ln \left[\frac{H+a}{R_{c}}\right]
$$

This analytical solution was evaluated for the following parameter values:

$$
\begin{gathered}
K_{1}=1 \quad T_{c}=1 \quad T_{s}=0 \\
H=4.8 m \quad R_{c}=1 m
\end{gathered}
$$

The resulting analytical temperature distribution is presented in Figure 12. 


\subsubsection{Numerical Solution}

The FLASH computer code was set up to model the conduction heat transfer in the idealized porous medium. Only a half space was modeled because of the plane of symmetry. The temperature along the top boundary of the domain was set at $T_{s}=0$ while the temperature at the cylinder surface was fixed at $T_{c}=1$. The left boundary of the domain was treated as a natural or zero gradient boundary condition. To better satisfy the conditions at the right and bottom boundaries, the analytical solution was used to calculate and specify the boundary values.

A finite element mesh was generated that conformed to the cylinder and half space geometry. The mesh extended $15 \mathrm{~m}$ in the $\mathrm{x}$-direction and $-30 \mathrm{~m}$ in the $\mathrm{y}$-direction. The mesh consisted of 119 isoparametric, quadrilateral elements with a total of 386 nodes. The FLASH computer code was run in the steady-state mode to yield a direct solution to heat transport problem. The numerical solution was compared with the analytical solution at all interior node locations. Both solutions agreed exceptionally well with the maximum difference of about $5 \times 10^{-4}{ }^{\circ} \mathrm{C}$. 


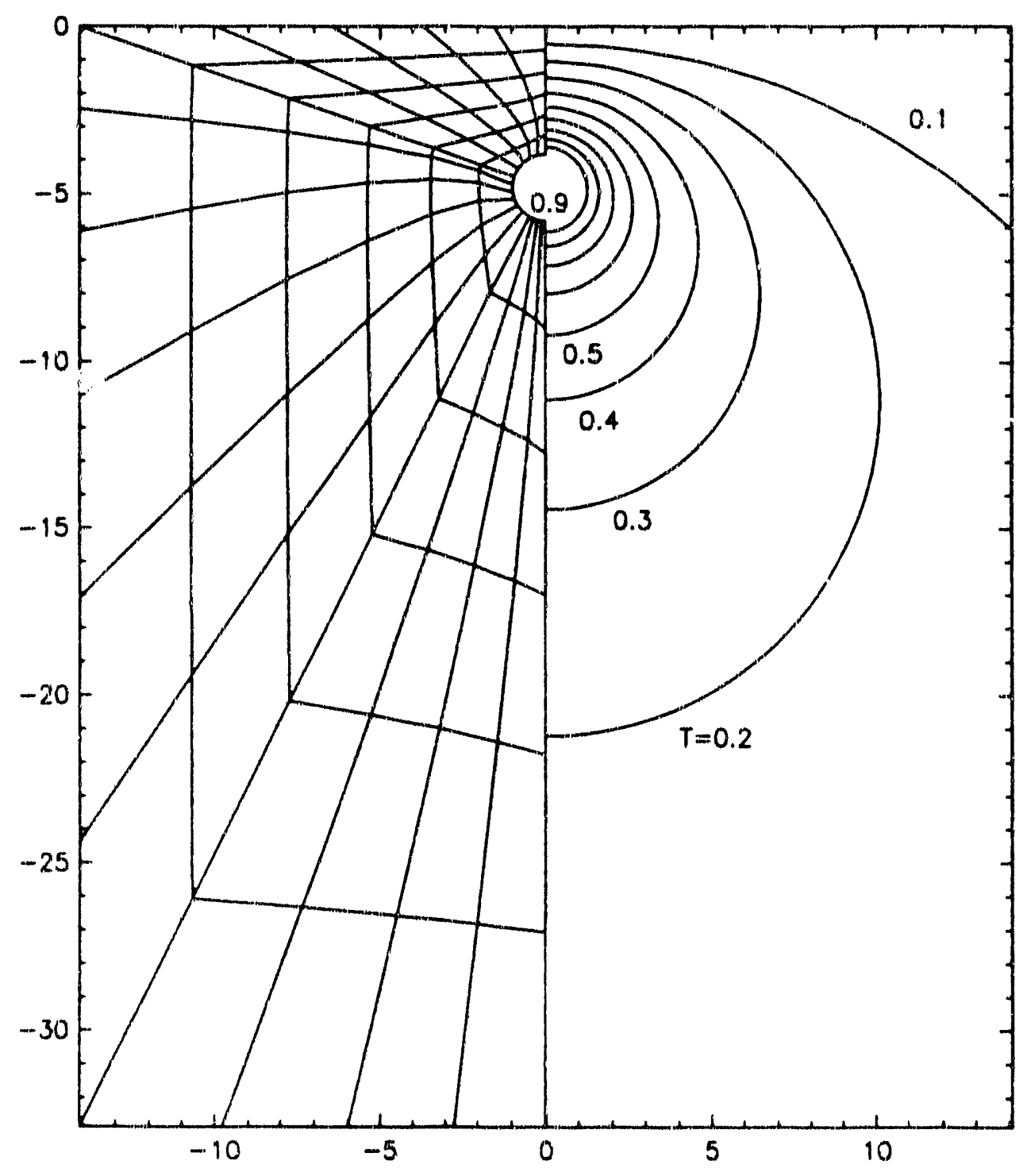

Figure 12. Comparison of Soil Tenperature Distributions computed with FI.ASH and Analytical Solution 


\subsection{INPUT GUIDE}

\subsection{Introduction}

To apply the FLASH computer code to a given problem, the user constructs an input file that specifies the unique characteristics of the simulation. These characteristics typically include the hydraulic and/or thermal properties of the porous medium, initial and boundary conditions, computational grid, and solution procedure. The input file for the FLASH code is constructed using a narrative style command sequerse. Input is read into the cole using an algorithm that is designed with three basic objectives in mind: (1) to permit the user to incorporate detailed documentation of input data, (2) provide a flexible assembly of the data stream, and (3) allow user to easily construct input files for new applications using existing data files.

These objectives were met by a general and user-friendly input scheme with the following features:

o comment lines may be inserted in any location to document data sources, units, assumptions and conditions,

o data are entered as free-form, case and order independent,

o simulation specified by use of command instructions and special keywords,

o soil properties, initial conditions, and computational mesh may be input from external files,

o default parameters are set for unspecified input, and

o input data is processed and checked for consistency with general specifications.

The above features minimize, to a great degree, the need to refer to the input guide during data file preparation. The following conventions are used in constructing the input data file for a specific simulation:

0 In using the planar coordinates $(x, z)$ or radial coordinates $(r, z)$, the $z$-coordinate is positive upwards,

O All hydraulic properties are in units of centimeters and seconds; all thermal properties are in units of calories,

() Numerical values are input in a list-directed format,

0 Command :-atructions and keywords start in the first three columns of the file, and

o The pound ign ( $\$$ is used to designated a comment or text line. 


\subsection{Summary of Command Instructions}

In the present version of the FLASH code, version 3.0, the input file is constructed using up to fifteen (15) unique command instructions. The available commands are listed and briefly explained below:

o ECHO - specifies the requirement for echo of the input file

o TITLE - declares a unique run identifier to be input

o TEXT - declares a sequence of text lines

o CONTROL - specifies the simulation control parameters

o FILES - declares the use of external files

o SOLVE - specifies the solution procedure

o TIME PLANE - lists the time intervals and output planes

o INITIAL CONDITION - keys the input of initial conditions

o FIXEDBC - keys input of Dirichlet boundary conditions

o FLUXBC - keys input of Neumann boundary conditions

o GRID - keys input of finite element mesh

o PROPERTIES - keys input of hydraulic and thermal properties

- TABLES - keys input of characteristic and hydraulic conductivity curve data

- THERMAL - keys input of thermal conductivity curve data

o OUTPUT - defines hard copy output requirements

Of the above command instructions, the ECHO, TEXT, FILES, THERMAL and OUTPUT commands are optional. More detailed descriptions and representative examples of the individual command instructions and keywords are presented in the next subsection.

\subsection{Description of Input Stream}

As outlined previously, the input file is constructed using a combination of the 15 command instructions. Each unique command is used by the computer code to specify the nature of the input data and keywords that follow. With few exceptions, unspecified data, parameters and/or unused keywords are assigned default values. The keywords described in the following subsections are shown in italics.

\subsubsection{ECHO Command}

The ECHO command is utilized to produce a listing of the complete input data file. This listing is appended to the standard report file, (i.e, hard copy output) generated by the computer code. The echo of the input file can be eliminated by use of the command ECHO SUPPRESS or SUPPRESS ECHO. 


\subsubsection{TITLE Command}

The TITLE command line is usually the first input line in the data file. This line is followed by single line of text which becomes the unique title and run identifier. This title is written to the report file and to all binary output files as a file header. Also writien to these output files is a numerical identifier which is a combination of the date and time. Additional lines of text may be placed after the title, however, these lines of text are not used elsewhere.

\subsubsection{TEXT Command}

The TEXT cornmand keys the input routine that a block of text will follow; the purpose of this text is to document the unique aspects of the input data or simulation. Any number of text lines can be inserted following the TEXT command. It is recommended that this option be used to identify the user, explain the nature of the simulation, identify the particular case or run number, date of the computer run, list key assumptions, etc.

\subsubsection{CONTROL Command}

Specification of the simulation problem and solution procedure is accomplished using the CONTROL command. Following this command, the user utilizes various keywords to define: (1) processes to be modeled, (2) characteristics of the boundary value problem, (3) computational solution procedures, (4) coordinate system to be used, and (5) output print control. The keywords can be used with other descriptions; the input is case and order independent.

To specify the processes to be modeled, the following alternative keywords can be used:

o Heat Transfer or Heat Transport

o Fluid Flow, Unsaturated Flow, Richards Flow Equation

- Dupuit or Dupuit-Forchheimer Flow Equation

o Horizontal Flow Equation

To suppress either process, the above keywords are preceded with: No, Non, Dont, Don't.

Definition of the boundary value problem is accomplished with the use of the following keywords:

o Uniform Initial C'onditions or Nonuniform Initial Conditions

o Specified, Flux, or Mixed Boundary Conditions

o Time-dependent, Transient, or Steady-State Mode 
In the latter specification, the keyword Mode must appear in the text line. Use of first type boundary conditions are allowed with both the Specified and Mixed keywords. Similarly, prescribed fluxes are allowed with both the Flux and Mixed keywords. In addition, the specification of flux boundary conditions also requires specification of the type of flux model, i.e., constant flux, interpolation flux from a table, or use of an empirical formula. This specification is made by use of the keywords:

- Varying Flux Boundaries

o Constant, Interpolation or Empirical Flux Model

The empirical flux model must be coded in the appropriate routine by the user.

In order to specify the computational solution procedure, the user enters numerical values for: number of finite elements, number of nodes, number of iterations, and initial start time. In addition, the user selects: (1) iteration method, (2) type of shape functions, and (3) matrix solution method. The following keywords can be used:

o Picard or Newion Iteration

o Linear or Quadratic Shape Functions

o Band or Frontal Solver

The above are optional specifications; the code uses the following default specifications: (1) Newton iteration, (2) quadratic shape functions, and (3) band solver.

The code has the capability to solve the governing equations in either Cartesian or radial coordinates. Appropriate specification of the coordinate system is accomplished by use of the keywords: Cartesian $(\mathrm{x}, \mathrm{z})$ or Radial $(\mathrm{r}, \mathrm{z})$ Coordinates. If not specified, the code defaults to a Cartesian coordinate system.

Control of printed output is achieved by use of such keywords as: Echo All, Minimum Echo, Full Echo. The latter specification should only be used for data debugging purposes.

\subsubsection{FILES Command}

Use of the FILE command indicates that next lines of input will define the use of external files. External files are defined for specific input and/or output functions. For example, the rode allows the user to read or write restart files, output numerical solutions for post-processing, read the finite element grid (i.e., element-node table and node coordinates), initial conditions, soil-hydraulic property tables, and data for velocity field computations. The following are examples of the applicable keywords:

- Read Restart Input or Write Restart Output

o Write Simulation Results 
o Read Mesh Input

o Read Initial Conditions or Write Initial Conditions

o Read Soil Properties

o Write Velocity Output Data

Any of the input or output operations can be suppressed by preceding the keyword string with: No, Dont, or Don't. The code defaults to setting of no external inputs or outputs.

\subsubsection{SOLVE Command}

The SOLVE command is used to indicate the input of six parameters that are used in the solution procedure. These parameters consist of: (1) the time integration factor, $\alpha$, (2) relative error criteria, $\varepsilon_{\max }$, (3) maximum change in pressure head, $\tau_{\psi}$, (4) maximum change in temperature, $\tau_{r},(5)$ grid scale factor in the $x$-direction, $s_{x}$ and $(6)$ grid scale factor in the $y$-direction, $s_{y}$. These numerical values are read as list-direct input.

\subsubsection{TIME PLANE Command}

The TIME PLANE command is used to specify the time domain for a time-dependent simulation heat or fluid flow. This command is followed by two columns of numerical input consisting: (1) number of subintervals and (2) output time plane in days. Each of input defines an interval of time referenced to the initial start time or the previous interval. If the user enters a value of 1 for the number of subintervals, the computer code will calculate the appropriate number from the initial interval. Time-stepping within a given time interval is automatically varied to maintain a constant truncation error.

An example of the TIME PLANE command and input is shown below:

TIME PLANE

\# No. Steps Time (days)

$10 \quad 0.1$

$1 \quad 1.0$

If the steady-state simulations option is selected under the CONTROL command, these data are simply ignored.

\subsubsection{INITIAL CONDITIONS Command}

Time-dependent simulations require the specification of initial conditions for each computational node. This specification is accomplished using the INITIAL CONDITIONS command. The command is followed by three columns on numerical input consisting of: (1) node number, (2) initial temperature ${ }^{\circ} \mathrm{C}$, and (3) initial pressure head $(\mathrm{cm})$. This command is typically used to specify uniform initial conditions. An example is shown below: 


\section{INITIAL CONDITIONS \\ \# $\mathrm{N} \quad \mathrm{T}(\mathrm{C}) \quad \mathrm{H}(\mathrm{cm})$ \\ $1 \quad T_{0} \quad \psi_{0}$}

For cases where the initial conditions vary over the entire grid, the use of external file input (see the FILES command) is recommended.

\subsubsection{FIXEDBC Command}

To define the boundary value problem, the user will usually need to input the Dirichlet boundary conditions, i.e., the known temperature or pressure head values at specific nodes. The FIXEDBC command is used to que the input of node points with fixed values. The command is followed by from five to eleven columns of numerical values consisting of: (1) node number, $n$ (2) boundary type index, $N 1$, for temperature, (3) boundary type index, $N 2$, for pressure head, (4) fixed temperature value, $T_{B}\left({ }^{\circ} \mathrm{C}\right)$ and (5) up to seven coefficients to define the transient fixed pressure head (total head for saturated flow) value, $\psi_{B}(\mathrm{~cm})$, where

$$
\psi_{B}=A+B t+C t^{2}+D \cos (E t)+F \sin (G t) \text {. }
$$

\section{FIXEDBC}

$\begin{array}{rrrrcccccccc}\# & \mathrm{n} & \mathrm{N} 1 & \mathrm{~N} 2 & T\left({ }^{\circ} C\right) & \psi(\mathrm{cm}) & & & & & & \\ & 1 & 0 & 1 & T_{B} & A & B & C & D & E & F & G\end{array}$

A constant fixed pressure head can be obtained by only specifying the $A$ coefficient. The boundary type index is set to 0 for a computational or "free" node or set to 1 for a non-computational or "fixed" node.

\subsubsection{FLUXBC Command}

In a number of cases, the user will need to input flux or Neumann boundary conditions at specific nodes. The FLUXBC command is used to key the input of node points with prescribed flux values. The command is followed four groups of numerical values consisting of: (1) heat flux (cal/s) and fluid flux ( $\mathrm{cm} / \mathrm{s})$, (2) list of prescribed flux nodes each having the previously defined flux value, (3) list of unit gradient nodes, and (4) a node number and coefficients for defining a transient volumetric flux. This transient flux is evaluated by

$$
Q-A+B t+C t^{2}+D \cos (E t)+F \sin (G t) \text {. }
$$

The list of nodes for (2) and (3) are entered in groups of 8 . An example is given below: 


\section{FLUXBC}

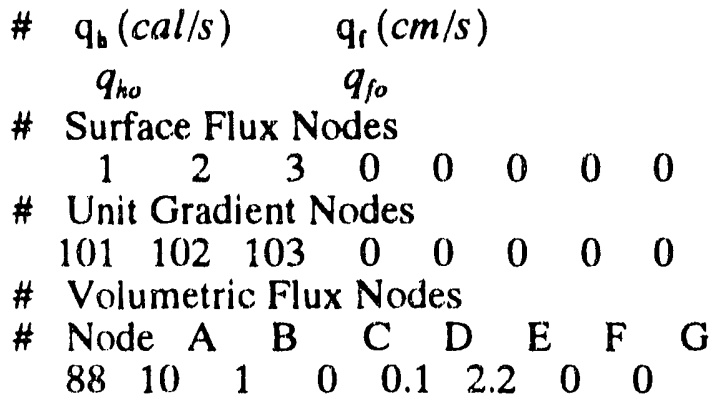

The unit gradient conditions can also be established using the "natural" boundary condition of zero pressure head gradient. This boundary condition automatically imposed on boundary nodes that are not designated as Dirichlet boundary condition nodes.

\subsubsection{GRID Command}

The FLASH code solves the governing equations on a finite element mesh composed of line, triangular, and/or quadrilateral elements. This mesh is defined in terms of an element-node table and list of node coordinates. This information can be entered into the input file using the GRID command. Following this command, the 11 column table consisting of: (1) the element number, (2) the corresponding node numbers listed in counter-clockwise order, (3) the element material number, and (4) element ordering index is entered. The last entry in the table must be entered to complete the input block; however, it is only used if the frontal solver option is selected under the CONTROL command. This index defines the order in which the frontal matrix solver will proceed (Hinton and Owen, 1977). The element-node table is followed by a 3 column input block consisting of: (1) node number, (2) $x$-coordinate location, and (3) $z$-coordinate location. A three element mesh which consists of a quadrilateral, triangle, and a line element superimposed between the these two elements is shown in Figure 13.

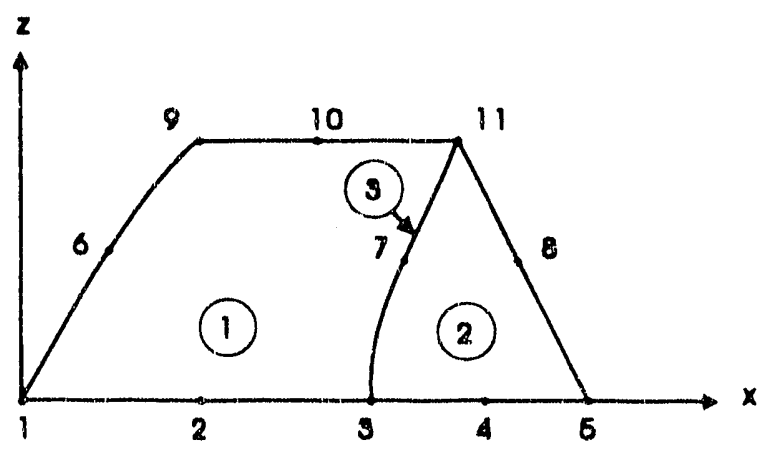

Figure 13. Sample Finite Element Mesh 
The corresponding GRID input is shown below:

GRID

\# Element-node table for example FE mesh

\begin{tabular}{|c|c|c|c|c|c|c|c|c|c|}
\hline $\begin{array}{r}\text { m } \\
1 \\
2 \\
3\end{array}$ & $\begin{array}{r}\text { N1 } \\
1 \\
3 \\
3\end{array}$ & $\begin{array}{r}\text { N2 } \\
2 \\
4 \\
7\end{array}$ & $\begin{array}{r}\text { N3 } \\
3 \\
5 \\
11\end{array}$ & $\begin{array}{r}\text { N4 } \\
7 \\
8 \\
0\end{array}$ & $\begin{array}{r}\text { N5 } \\
11 \\
11 \\
0\end{array}$ & $\begin{array}{r}\text { N6 } \\
10 \\
7 \\
0\end{array}$ & $\begin{array}{r}\text { N7 } \\
9 \\
0 \\
0\end{array}$ & $\begin{array}{r}\text { N8 } \\
6 \\
0 \\
0\end{array}$ & $\begin{array}{r}\mathrm{km} \\
1 \\
1 \\
1\end{array}$ \\
\hline
\end{tabular}

\begin{tabular}{|c|c|c|}
\hline Node & point lo & ations \\
\hline $\mathbf{N}$ & $X(\mathrm{~cm})$ & $\mathrm{Z}(\mathrm{cm})$ \\
\hline$A^{*}$ & 0.0 & 0.0 \\
\hline 2 & 0.5 & 0.0 \\
\hline 3 & 1.0 & 0.0 \\
\hline 4 & 1.5 & 0.0 \\
\hline 5 & 2.0 & 0.0 \\
\hline etc & etc & etc \\
\hline
\end{tabular}

The above data are loaded into the code using a list-directed read. In practical applications, the mesh is composed of thousands of elements and nodes; thus, it is more convenient to read the above information from an external file using the FILES command.

\subsubsection{PROPERTIES Command}

The stratigraphic features of the porous medium generally exhibit distinct thermal and/or hydraulic properties. The PROPERTIES command is used to enter these properties for each material type. Following this command, the following data are entered: (1) material number, (2) volumetric heat capacity $C_{h}\left(\mathrm{cal} / \mathrm{cm}^{3}-{ }^{\circ} \mathrm{C}\right)$, (3) thermal conductivity $K_{l}$ (cal/cm-s- ${ }^{\circ} \mathrm{C}$ ), (4) specific storage $S_{s}(1 / \mathrm{cm}),(5)$ saturated hydraulic conductivity $K_{x}(\mathrm{~cm} / \mathrm{s})$, (6) saturated hydraulic conductivity $K_{z}(\mathrm{~cm} / \mathrm{s})$, (7) saturated moisture content $\theta_{s}$ or porosity, and (8) line-element width $b(\mathrm{~cm})$. An example input is shown below:

\section{PROPERTIES}

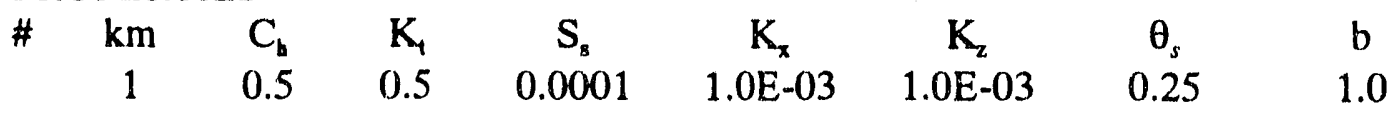

A line of data is entered for each material type and designated by the material number $\mathrm{km}$.

\subsubsection{TABLES Command}

The TABLES command is used to input the characteristic and relative hydraulic conductivity curve data. These data are typically generated by first fitting van Genuchten (1980), Campbell (1985) or Brooks-Corey (Corey, 1986) formulas to laboratory data. These analytical formulas are then evaluated to produce the tabular data. The tabular data consists of three columns: (1) pressure head $\psi,(2)$ volumetric moisture content $\theta$, and (3) relative hydraulic conductivity $K_{r}$. 
Typically, the tabular data should be ordered from zero pressure head to the lowest (i.e., most negative) pressure head. However, the input routine will accept pressure head as a positive quantity and will automatically sort the data and add the appropriate sign to the pressure head. It is highly recommended that the data be generated uniformly in the log space and that each variable be calculated from the analytical formulas to at least five significant figures. One table for each material type must be entered following the TABLES command. An example input table is shown below:

\section{TABLES}

\# Material Properties for soil type 1

$\begin{array}{ccc}\text { \#hi }(\mathrm{cm}) & \text { Theta } & \mathrm{Kr} \\ 0.00000 \mathrm{E}+00 & 0.25000 & 1.00000 \mathrm{E}+00 \\ -1.00000 \mathrm{E}-01 & 0.24999 & 9.99999 \mathrm{E}-01 \\ -2.00000 \mathrm{E}-01 & 0.24990 & 9.99950 \mathrm{E}-01 \\ -3.00000 \mathrm{E}-01 & 0.24910 & 9.99100 \mathrm{E}-01 \\ \text { etc } & \text { etc } & \text { etc }\end{array}$

The keyword Material must appear in the comment card before the tabular data.

Alternate keywords such as Soil-Hydraulic, Soil Hydraulic, Soil-Properties, Soil Properties, and Characteristic. It is recommended that 30 or more points be used in defining the characteristic and relative conductivity curves. For practical applications with several tables, it is more convenient to load these data using an external file (see FILES command).

\subsubsection{THERMAL Command}

In certain special applications, it is important to account for the dependent of the thermal conductivity on moisture content level or pressure head. The THERMAL command is an optional command that allows the user to enter tabular data defining the appropriate functional relationship. Following this command, two columns of data are entered: (1) pressure head and (2) relative thermal conductivity. The input structure is similar to that described previously under the TABLES command.

\subsubsection{OUTPUT Command}

The OUTPUT command, which is optional, can be used by the user to suppress selected portions of the report file. For example, the usually lengthy element-node table and node point coordinates can be suppressed by following this command with the keyword Grid. Similarly, the lengthy list of initial conditions can be suppressed using the keyword Initial. 


\section{ACKNOWLEDGMENTS}

The authors wish to thank a number of individuals that contributed to this project. First and foremost, the authors thank Ms. M. Beth Sussman, Technology Programs, for her patience during the conduct of this study. The authors acknowledge the contributions of Ms. Annette Schafer-Perini for modifying the FLASH code to solve the Dupuit-Forchheimer equation. The authors also thank Mr. Tony R. Moser of EG\&G for his assistance with preparation of graphs and illustrations. 


\section{REFERENCES}

Arfken, G., Mathematical Methods for Physicist, Academic Press, New York, NY (1970).

Arnett, R. C., R. C. Martineau, and M. J. Lehto, "Preliminary Numerical Model of Radionuclide Transport in the Snake River Plain Aquifer Near the Idaho National Engineering Laboratory," EGG-WM-8820, EG\&G Idaho, Inc., Idaho Falls, ID (1990).

Baca, R. G., I. P. King, and W. R. Norton, "Finite Element Models for Simultaneous Head and Moisture Transport in Unsaturated Soils," Proceedings of the Second International Conference on Finite Elements in Water Resources, Imperial College, Pentech Press, London, UK (1978).

Baca, R. G. and D. W. Langford, "MAGNUM-2D - A Numerical Model for Coupled Heat Transfer and Groundwater Flow in Fractured-Porous Media: Model Theory, Numerical Methods, and Computational Tests," (Draft), Rockwcll Hanford Operations, Richland, WA (1986).

Baca, R. G., and D. W. Langford, "CHAINT - A Numerical Model for Radionuclide Transport with Decay Chains in Fractured-Porous Media: Model Theory, Numerical Methods, and Computational Tests," (Draft), Rockwell Hanford Operations, Richland, WA (1986).

Baca, R. G., R. C. Arnett, and D. W. Langford, "Modelling Fluid Flow in Fractured-Porous Masses by Finite Element Techniques," International Journal for Numerical Methods in Fluids, Vol. 4, pp. $337-348$ (1984).

Baca, R. G., "Configuration Management and Software Control Procedure for Subsurface Flow and Transport Simulation Codes," EGG-WM-9103, EG\& G Idaho, Inc., Idaho Falls, ID (1990).

Baca, R. G., and S. O. Magnuson, "Independent Verification and Benchmark Testing of the UNSAT-H Computer Code, Version 2.0," EGG-BEG-8811, EG\&G Idaho, Inc., Idaho Falls, ID (1990).

Baca, R. G., S. O. Magnuson, H. D. Nguyen, and P. Martian, "A Modeling Study of Water Flow in the Vadose Zone Beneath the Radioactive Waste Management Complex," EGG-GEO-10068, EG\&G Idaho, Inc., Idaho Falls, ID (1992).

Bachmat, Y., J. Bredehoeft, B. Andrews, D, Holt, and S. Sebastian, Ground-Water Management: The Use of Numerical Models, Water Resources Monograph 5, American Geophysical Union, Washington, DC (1980). 
Bishop, C. W., "Hydraulic Properties of Vesicular Basalt," MS Thesis, University of Arizona, Tucson, AZ (1991).

Borghese, J. V., "Hydraulic Characteristics of Soil Cover, Subsurface Disposal Area, Idaho National Engineering Laboratory," MS Thesis, Univ. of Idaho, Moscow, ID (1988).

Burnett, D. S., Finite Element Analysis, Addison-Wesley Publishing Company, Reading, MA (1987).

Case, M. J., S. J. Maheras, M. A. Mckenzie-Carter, M. E. Sussman, and P. Voilleque, "Radioactive Waste Management Complex Performance Assessment," EGG-WM-8773, EG\&G Idaho, Inc., Idaho Falls, ID (1989).

Celia, M. A., E. T. Bouloutas, and R. L. Zarba, "A General Mass-Conservative Numerical Solution for the Unsaturated Flow Equation," Water Resources Research, Vol. 26, No. 7, pp. 1483-1496 (1990).

Celia, M. A. "The One-Dimensional Princeton Unsaturated Code," Department of Civil Engineering, Water Resources Program, Princeton, NJ (1991).

Cuthill, E., "Several Strategies for Reducing the Bandwidth of Matrices," in Sparse Matrices and their Applications, eds. D. J. Rose and R. A. Willoughby, Plenum Press, New York, NY (1972).

Davis, L. C. and J. R. Pittman, "Hydrological, Meteorological, and Geohydrological Data for an Unsaturated Zone Study Near the Radioactive Waste Management Complex, Idaho National Engineering Laboratory, Idaho--1987," Report 90-114, U.S. Geological Survey, Idaho Falls, ID (1990).

EG\&G "Methodology for Compliance with DOE Order 5820.2A, Chapter III: Management of Low-Level Waste," DOE/LLW-75T, prepared by the National Low-Level Waste Management Program, EG\&G Idaho, Inc., Idaho Falls, ID (1988).

England, R. L., N. W. Kline, K. J. Ekblad, and R. G. Baca, "MAGNUM-2D Computer Code: User's Guide," RHO-CR-143 P, Rockwell Hanford Operations, Richland, WA (1986). Gerald, C. F. and P. O. Wheatley, Applied Numerical Analysis, Addison-Wesley Publishing Co., Reading, MA (1984).

Gibbs, N. E., W. G. Poole, Jr., and P. K. Stockmeyer, "A Comparison of Several Bandwidth and Profile Reduction Algorithms," Association for Computing Machinery Transactions of Mathematical Software, Vol. 2, pp. 322-330 (1976)

Hinton, E. and D. R. J. Owen, Finite Element Programming, Academic Press, New York, NY (1977). 
Hood, P., "Frontal Solution Program for Unsymmetric Matrices," International Journal for Numerical Methods in Engineering, Vol. 10., pp. 329-400 (1976).

Humphrey, T. G., T. H. Smith, and M. C. Pope, "Projected Subsurface Migration of

Radionuclides from Buried Idaho National Engineering Laboratory Transuranic

Waste," Nuclear Technology, Vol. 58, pp. 136-149 (1982).

Huyakorn, P. S. and G. F. Pinder, Computational Methods in Subsurface Flow, Academic

Press, New York, NY (1983).

Kaminsky, J. F., "Insitu Characterization of Unsaturated Hydraulic Properties of Surficial

Sediments adjacent to the Radioactive Waste Management Complex, Idaho National

Engineering Laboratory, Idaho," MS Thesis, Idaho State Univ., Pocatello, ID (1991).

King, I. P., "An Automatic Reordering Scheme for Simultaneous Equations derived from

Network Analysis," International Journal for Numerical Methods in Engineering, Vol.

2, pp. 525-533 (1970).

Kline, N. W., R. L. England, and R. G. Baca, "CHAINT Computer Code: User's Guide,"

RHO-CR-144 P, Rockwell Hanford Operations, Richland, WA (1986).

Knutson, C. F., K. A. McCormick, R. P. Smitì, W. R. Hackett, J. P. O'Brien, and J. C.

Crocker, "FY 89 Report - RWMC Vadose Zone Basalt Characterization,"

$E G G-W M-8949$, EG\&G Idaho, Inc., Idaho Falls, ID (1990).

Long, J. C. S., J. S. Remer, C. R. Wilson, and P. A. Witherspoon, "Porous Media Equivalents for Networks of Discontinuous Fractures," Water Resources Research, Vol. 18, No. 2 , pp. $645-658$ (1982).

Magnuson, S. O., R. G. Baca, and A. J. Sondrup, "Independent Verification and Benchmark Testing of the PORFLO-3 Computer Code, Version 1.0," EGG-BG-9175, EG\&G Idaho, Inc. Idaho Falls, ID (1990).

McElroy, D. L., "Vadose Zone Monitoring at the Radioactive Waste Management Complex at the Idaho National Engineering Laboratory, 1985-1989," EGG-WM-9229, EG\&G Idaho, Inc., Idaho Falls, ID (1990).

McElroy, D. L. and J. M. Hubbell, "Hydrologic and Physical Properties of Sediments at the Radioactive Waste Management Complex," EGG-WM-9147, EG\&G Idaho, Inc., Idaho Falls, ID (1990).

Mizell, S. A. and L. C. Hull, "Preliminary Modeling of Radionuclide Migration through the Subsurface at the INEL Radioactive Waste Management Complex using the Unsaturated Flow and Transport Model UNSAT," RE-PB-83-0.38, EG\&G Idaho, Inc., Idaho Fal!s, ID (1983). 
Oster, C. A., "Review of Ground-Water Flow and Transport Models in the Unsaturated Zone," NUREG/CR-2917, PNL-4427, Battelle-Pacific Northwest Laboratory, Richland, WA (1982).

Pittman, J. R. "Hydrological and Meteorologic Data for an Unsaturated Zone Study near the Radioactive Waste Management Complex, Idaho National Engineering Laboratory, Idaho-1985-86," Report 89-74, U.S. Geological Survey, Idaho Falls, IJ (1989).

Pope, M. C. and H. W. Reno, "Modeling Radionuclide Transport in the Unsaturated Zone Beneath the Radioactive Waste Management Complex," (Draft Report), EG\&G Idaho, Inc., Idaho Falls, ID (1982).

RAE (Rogers and Associates Engineering), "DOE Site Performance Assessment Activities," DOE/LLW-99, prepared for EG\&G Idaho, Inc., Idaho Falls, ID (1990).

Rasmussen, T. C., D. D. Evans, and T. J. Nicholson, "Unsaturated Flow and Transport Through Fractured Rock Related to High-Level Waste Repositories, Final Report, Phase II," NUREG/CR-45, prepared by the Department of Hydrology and Water Resources, University of Arizona, Tucson, AZ (1987).

Rightmire, C. T. and B. D. Lewis, "Hydrology and Geochemistry of the Unsaturated Zone, Radioactive Waste Managernent Complex, Idaho National Engineering Laboratory, Idaho," Report 87-4198, U. S. Geological Survey, Idaho Falls, ID (1987).

Robertson, J. B. "Digital Modeling of Radioactive and Chemical Waste Transport in the Snake River Plain Aquifer at the National Reactor Testing Station, Idaho," U.S.G.S. Open File Report IDO-22054, Idaho Falls, ID (1974).

Snow, D. T., "Anisotropic Permeability of Fractured Media," Water Resources Research, Vol. 5, pp. 1273-1288 (1969).

Strang, G. and G. Fix, An Analysis of the Finite Element Method, Prentice-Hall, Englewood Cliffs, NJ (1973).

Tewarson, R. P., Sparse Matrices, Academic Press, New York, NY (1973).

van Genucthen, M. T., "A Closed-Form Equation for Predicting the Hydraulic Conductivity of Unsaturated Soils," Soil Science Society of America Journal, Vol. 44, pp. 892-898 (1980).

Vigil, M. J., "Estimate of Water Pits During Flooding Events", EDF-BWP-12, EG\&G Idaho, Inc., ldaho Falls, ID (1988), 


\section{APPENDIX I - SAMPLE INPUT FILES FOR TEST PROBLEMS}

This appendix presents condensed versions of the input files prepared for two of the computational examples described in section 5.0. The two examples consist of: (1) partially saturated flow in a dry soil and (2) heat transport from a buried heat source. Certain portions of the input files have been omitted because of their length. These portions, which include the grid definition and soil property tables, can be easily recontructed by the user from information given in section 5.0 .

\section{A-1 Summary of Input File for Computational Example 1}

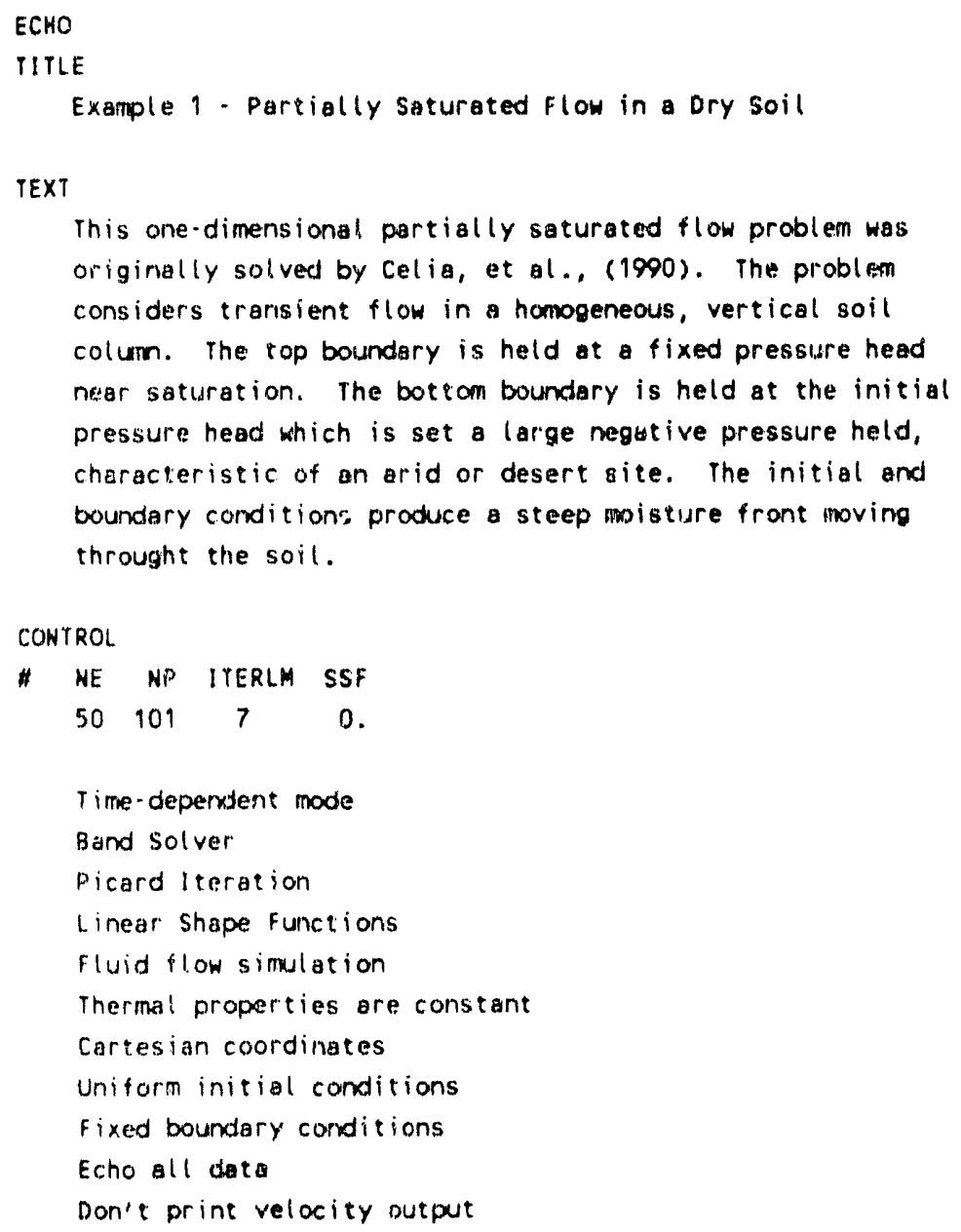




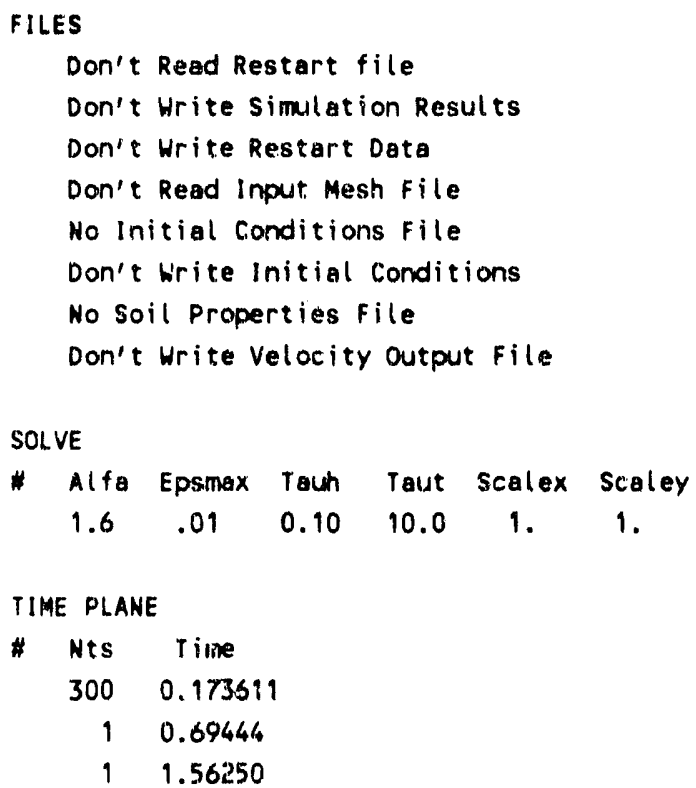

$\begin{array}{rrrrrrrrrrr}48 & 95 & 96 & 97 & 0 & 0 & 0 & 0 & 0 & 1 & 48 \\ 49 & 97 & 98 & 99 & 0 & 0 & 0 & 0 & 0 & 1 & 49 \\ 50 & 99 & 100 & 101 & 0 & 0 & 0 & 0 & 0 & 1 & 50 \\ 1 & & 0.000 & 0.000 & & 0.00 & 0.00 & & \\ 2 & & 0.000 & -1.000 & & 0.00 & 0.00 & & \\ 3 & & 0.000 & -2.000 & & 0.00 & 0.00 & \\ 4 & 0.000 & -3.000 & & 0.00 & 0.00 & \\ 5 & 0.000 & -4.000 & & 0.00 & 0.00 & \\ 6 & 0.000 & -5.000 & & 0.00 & 0.00 & \\ 7 & 0.000 & -6.000 & & 0.00 & 0.00 & & \end{array}$




$\begin{array}{rrrrr}95 & 0.000 & -94.000 & 0.00 & 0.00 \\ 96 & 0.000 & -95.000 & 0.00 & 0.00 \\ 97 & 0.000 & -96.000 & 0.00 & 0.00 \\ 98 & 0.000 & -97.000 & 0.00 & 0.00 \\ 99 & 0.000 & -98.000 & 0.00 & 0.00 \\ 100 & 0.000 & -99.000 & 0.00 & 0.00 \\ 101 & 0.000 & -100.000 & 0.00 & 0.00\end{array}$

PROPERTIES

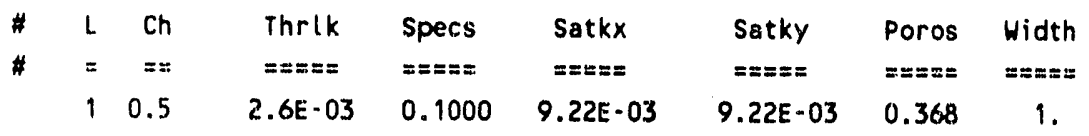

TABLES

* 101 Hydraulic \& Characteristic Curves for Yolo light Clay

$\begin{array}{ccc}\text { \#hi } & \text { Theta } & \text { RelK } \\ -0.150 E+04 & 0.1073 & 0.5527 E-08 \\ -0.145 E+04 & 0.1075 & 0.6441 E-08 \\ -0.140 E+04 & 0.1077 & 0.7506 E-08 \\ -0.135 E+04 & 0.1079 & 0.8747 E-08 \\ -0.131 E+04 & 0.1081 & 0.1019 E-07 \\ -0.127 E+04 & 0.1083 & 0.1188 E-07 \\ -0.122 E+04 & 0.1085 & 0.1384 E-07 \\ -0.118 E+04 & 0.1087 & 0.1613 E-07 \\ -0.114 E+04 & 0.1089 & 0.1880 E-07 \\ -0.110 E+04 & 0.1092 & 0.2190 E-07 \\ -0.107 E+04 & 0.1094 & 0.2552 E-07 \\ -0.103 E+04 & 0.1097 & 0.2974 E-07 \\ -0.997 E+03 & 0.1100 & 0.3466 E-07 \\ -0.964 E+03 & 0.1102 & 0.4038 E-07 \\ -0.932 E+03 & 0.1105 & 0.4706 E-07 \\ -0.901 E+03 & 0.1108 & 0.5483 E-07 \\ -0.870 E+03 & 0.1111 & 0.6389 E-07\end{array}$

\section{(Lines Omitted)}

$\begin{array}{lll}-0.535 E+02 & 0.2316 & 0.1120 E-01 \\ -0.517 E+02 & 0.2349 & 0.1267 E-01 \\ -0.500 E+02 & 0.2384 & 0.1431 E-01\end{array}$

OUTPUT

Echo all Input Data 


\section{A-2 Summary of Input File for Computational Example 3}

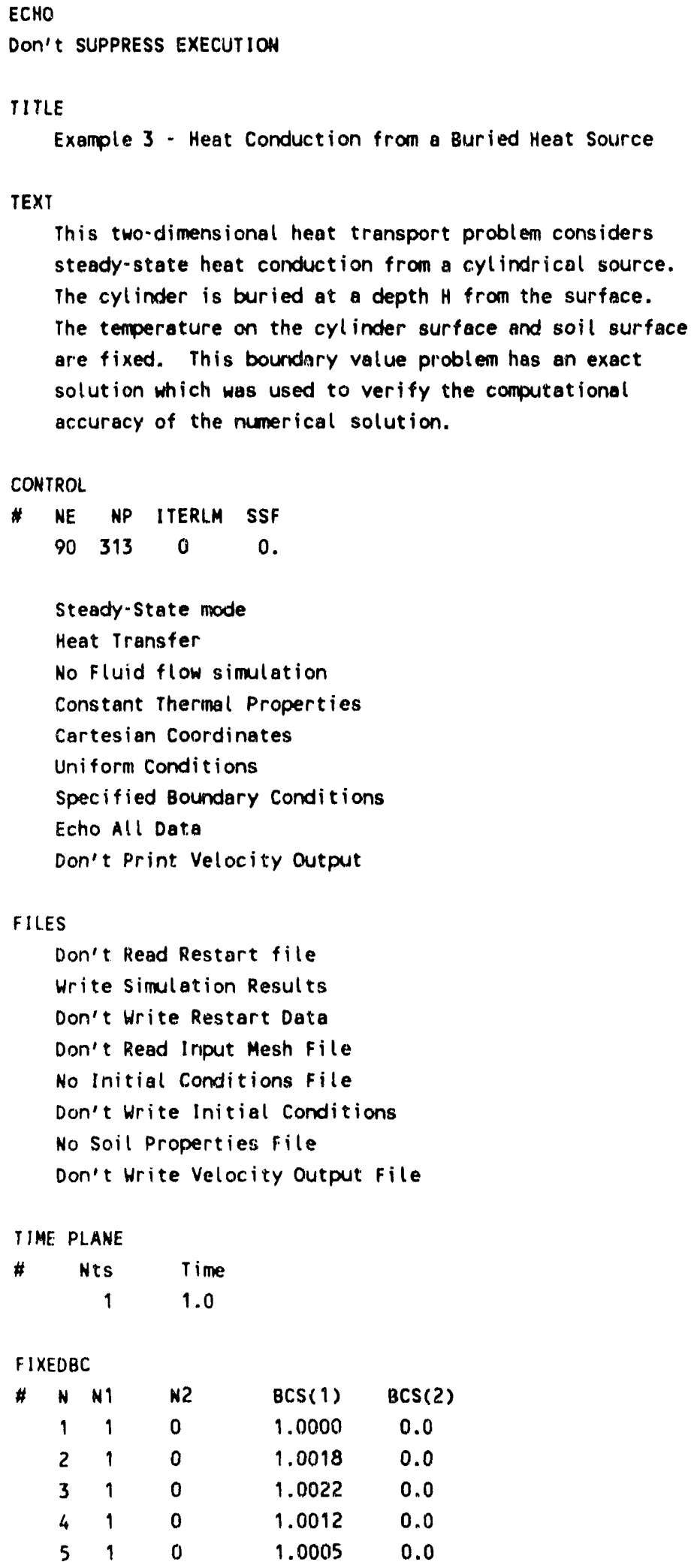

$\begin{array}{ccccc}\text { \# } & \text { N1 } & \text { N2 } & \text { BCS(1) } & \text { BCS(2) } \\ 1 & 1 & 0 & 1.0000 & 0.0 \\ 2 & 1 & 0 & 1.0018 & 0.0 \\ 3 & 1 & 0 & 1.0022 & 0.0 \\ 4 & 1 & 0 & 1.0012 & 0.0 \\ 5 & 1 & 0 & 1.0005 & 0.0\end{array}$




$\begin{array}{lllll}308 & 1 & 0 & 0.1208 & 0.0 \\ 309 & 1 & 0 & 0.1236 & 0.0 \\ 310 & 1 & 0 & 0.1256 & 0.0 \\ 311 & 1 & 0 & 0.1269 & 0.0 \\ 312 & 1 & 0 & 0.1276 & 0.0 \\ 313 & 1 & 0 & 0.1278 & 0.0\end{array}$

GRID

\begin{tabular}{|c|c|c|c|c|c|c|c|c|c|c|}
\hline$\# \quad E L$ & LEMENT & DDE T & & & & & & & & \\
\hline N & $\cdots$ & . & $\cdots$ & NOP & ...... & $\cdots$ & . & $\cdots$ & IMAT & NFIXH \\
\hline 1 & 1 & 2 & 3 & 13 & 20 & 19 & 18 & 12 & 1 & 1 \\
\hline 2 & 3 & 4 & 5 & 14 & 22 & 21 & 20 & 13 & 1 & 2 \\
\hline 3 & 5 & 6 & 7 & 15 & 24 & 23 & 22 & 14 & 1 & 3 \\
\hline 4 & 7 & 8 & 9 & 16 & 26 & 25 & 24 & 15 & 1 & 4 \\
\hline 5 & 9 & 10 & 11 & 17 & 28 & 27 & 26 & 16 & 1 & 5 \\
\hline 6 & 18 & 19 & 20 & 30 & 37 & 36 & 35 & 29 & 1 & 6 \\
\hline 7 & 20 & 21 & 22 & 31 & 39 & 38 & 37 & 30 & 1 & 7 \\
\hline 8 & 22 & 23 & 24 & 32 & 41 & 40 & 39 & 31 & 1 & 8 \\
\hline 9 & 24 & 25 & 26 & 33 & 43 & 42 & 41 & 32 & 1 & 9 \\
\hline
\end{tabular}

\section{(Lines Omitted)}

\begin{tabular}{|c|c|c|c|c|c|c|c|c|}
\hline 85 & 2.85 & 286 & 287 & 292 & 299 & 298 & 297 & 291 \\
\hline 86 & 287 & 288 & 289 & 293 & 301 & 300 & 299 & 292 \\
\hline 87 & 2.15 & 294 & 295 & 302 & 307 & 306 & 233 & 221 \\
\hline 88 & 295 & 296 & 297 & 303 & 309 & 308 & 307 & 302 \\
\hline 89 & 297 & 298 & 299 & 304 & 319 & 310 & 309 & 303 \\
\hline 90 & 290 & 300 & 301 & 305 & 313 & 312 & 311 & 304 \\
\hline 1 & & 0.000 & \multicolumn{2}{|c|}{-3.800} & & \multicolumn{2}{|c|}{0.00} & 0.00 \\
\hline 2 & & 0.131 & \multicolumn{3}{|c|}{$\cdot 3.812$} & \multicolumn{2}{|c|}{0.00} & 0.00 \\
\hline 3 & & 0.254 & \multicolumn{3}{|c|}{-3.837} & \multicolumn{2}{|c|}{0.00} & 0.00 \\
\hline 4 & & 0.369 & \multicolumn{3}{|c|}{-3.873} & \multicolumn{2}{|c|}{0.00} & 0.00 \\
\hline 5 & & 0.475 & \multicolumn{3}{|c|}{-3.921} & \multicolumn{2}{|c|}{0.00} & 0.00 \\
\hline 6 & & 0.574 & \multicolumn{3}{|c|}{-3.981} & \multicolumn{2}{|c|}{0.00} & 0.00 \\
\hline 7 & & 0.663 & \multicolumn{3}{|c|}{-4.053} & \multicolumn{2}{|c|}{0.00} & 0.00 \\
\hline 8 & & 0.745 & \multicolumn{3}{|c|}{-4.136} & \multicolumn{2}{|c|}{0.00} & 0.00 \\
\hline 9 & & 0.818 & \multicolumn{3}{|c|}{-4.232} & \multicolumn{2}{|c|}{0.00} & 0.00 \\
\hline 10 & & 0.883 & \multicolumn{3}{|c|}{-4.339} & \multicolumn{2}{|c|}{0.00} & 0.00 \\
\hline \multicolumn{9}{|c|}{ (Lines Omitted) } \\
\hline 305 & & 0.000 & \multicolumn{3}{|c|}{-29.893} & \multicolumn{2}{|c|}{0.00} & 0.00 \\
\hline 306 & & 11.865 & \multicolumn{3}{|c|}{-32.860} & \multicolumn{2}{|c|}{0.00} & 0.00 \\
\hline 307 & & 9.780 & \multicolumn{3}{|c|}{-32.860} & \multicolumn{2}{|c|}{0.00} & 0.00 \\
\hline 308 & & 7.825 & \multicolumn{3}{|c|}{-32.860} & \multicolumn{2}{|c|}{0.00} & 0.00 \\
\hline 309 & & 6.000 & \multicolumn{3}{|c|}{-32.860} & \multicolumn{2}{|c|}{0.00} & 0.00 \\
\hline 310 & & 4.305 & \multicolumn{3}{|c|}{-32.860} & 0.0 & & 0.00 \\
\hline 391 & & 2.740 & & .860 & & 0.0 & & 0.00 \\
\hline 312 & & 1.305 & & .860 & & 0.0 & & 0.00 \\
\hline 313 & & 0.000 & & .860 & & 0.0 & & 0.00 \\
\hline
\end{tabular}


PROPERTIES

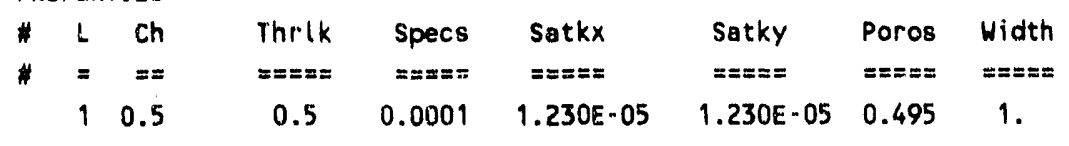

TABLES

\# 51 Hydraulic \& Characteristic Curves for Yolo light Clay
Shi
Theta
Relk
$0.000 E+00$
0.4950
$0.1000 E+01$
$-0.114 E+01$
0.4950
$0.9900 E+00$
$-0.130 E+01$
0.4950
$0.9874 E+00$
$-0.148 E+01$
0.4950
$0.9842 E+00$
$-0.169 E+01$
0.4950
$0.9801 E+00$
$-0.193 E+01$
0.4949
$0.9750 E+00$
$-0.219 E+01$
0.4948
$0.9687 E+O D$
$-0.250 E+01$
0.4946
$0.9609 E+00$
$-0.285 E+01$
0.4944
$0.9512 E+00$
$-0.325 E+01$
0.4940
$0.9392 E+00$
$-0.371 E+01$
0.4935
$0.9246 E+00$
$-0.423 E+01$
0.4928
$0.9067 E+00$

\section{(Lines Omitted)}

$\begin{array}{lll}-0.414 E+03 & 0.2572 & 0.2893 E-02 \\ -0.472 E+03 & 0.2499 & 0.2295 E-02 \\ -0.539 E+03 & 0.2430 & 0.1821 E-02 \\ -0.614 E+03 & 0.2365 & 0.1445 E-02 \\ -0.700 E+03 & 0.2302 & 0.1146 E-02\end{array}$

OUTPUT

Echo all Input Data 


\section{DISTRIBUTION LIST}

\section{OFFSITE}

D. J. Alexander

U. S. Department of Energy

Forrestal Bldg., MS RW-23-2

Washington, DC 20585

W. Barrish

INEL Oversight Program

$1410 \mathrm{~N}$. Hilton

Boise, ID 83706

J. S. Baldwin

Martin Marietta

Central Waste Management

Oak Ridge, TN 37831

A. J. Baker

Engineering Science and Mechanics

University of Tennessee

Knoxville, TN 37996-2030

A. K. Bhattacharyya

Department of Environmental Resources

Bureau of Radiation Protection

P. O. Box 2063

Harrisburg, PA 17120

K. H. Birdsell

Los Alamos National Laboratory

P. O. Box 1663

Los Alamos, NM 87545

T. N. Blandford

HydroGeoLogic, Inc.

1165 Herndon Pkwy, Suite 900

Herndon VA, 22070

G. Bloomsburg

Agricultural Engineering Department

University of Idaho

Moscow, ID 83843

A. Bumb

Fluor Daniel, Inc.

100 Fluor Daniel Drive

Greenville, SC 29607

T. C. Chee

U. S. Department of Energy

Research and Management Division

DP-123, A237

Germantown, MD 20545
D. L. Chery, Jr.

U. S. Nuclear Regulatory Commission

MS-4H3

Washington, DC 20555

J. N. Chung

Mechanical and Material Engineering

Washington State University

Pullman, WA 99164-2920

R. B. Codell

U. S. Nuclear Regulatory Commission MS-4H3

Washington, DC 20555

J. R. Cook

Westinghouse Savannah River Company

Savannah River Laboratory

P. O. Box 616, Bldg. 773-43A

Aiken, SC 29802

J. C. Corey

Westinghouse Savannah River Site

P. O. Box A

Aiken, SC 29808

M. Cunnane

Golder Associates, Inc.

4104 148th Avenue NE

Redmond, WA 98052

J. Davis

Westinghouse Hanford

450 Hills St.

Richland, WA 99352

P. A. Davis

Sandia National Laboratories

Division 6416

P. O. Box 5800

Albuquerque, NM 87185

P. Dickman

U. S. Department of Energy

Waste Management Project Office

P. O. Box 14100

Las Vegas, NV 89114

M. R. Dolenc

Reynolds Electrical and Engineering $\mathrm{Co}$.

P. O. Box 98521

Las Vegas, NV 89193-8521 
F. H. Dove

IT Corporation

5301 Central Ave, N.E., Suite 700

Albuquerque, NM 87108

R. R. Eaton

Sandia National Laboratories

Fluid Mechanics and Heat Transfer Div.

Albuquerque, NM 87185

M. Ebra

Westinghouse Savannah River Company

Environmental Restoration Program

P. O. Box 616

Aiken, SC 29802

L. Ebeling

Reynolds Electrical and Engineering Co.

P. O. Box 98521

Las Vegas, NV 89193-8521

A. I. El-Kadi

Univ. of Hawaii at Manoa

Dept. of Geology and Geophysics

2525 Correa Road

Honolulu, HW 96822

C. G. Enfield

U. S. Environmental Protection Agency

Robert S. Kerr Environmental Lab

P. O. Box 1198

Ada, OK 74820

M. J. Fayer

Pacific Northwest Laboratory

P. O. Box 999, MS K6-77

Richland, WA 99352

J. I. Finnie

Civil Engineering Department

University of Idaho

Moscow, ID 83843

R. A. Freeze

Department of Geological Sciences

University of British Columbia

Vanco'sver, BC V6T 2B4, Canada

G. W. Gee

Pacific Northwest Laboratory

P. O. Box 999, MS K6-77

Richland, WA 99352
T. C. Gunderson

Los Alamos National Laboratory

P. O. Box 1663, MS K491

Los Alamos, NM 87545

D. Hillel

Dept. of Plant and Soil Science

University of Massachusets

12A Stockbridge Hall

Amherst, MA 01003

C. Y. Hung

U. S. Environmental Protection Agency

Office of Radiation Programs, ANR-460

401 M Street, S. W.

Washington, DC 20460

P. S. Huyakorn

HydroGeoLogic, Inc.

1165 Herndon Pkwy, Suite 900

Herndon, VA 22070

$V$. Ichimura

Chem-Nuclear Systems

P. O. Box 726

Barnwell, SC 29182

B. Izadi

Agricultural Engineering Dept.

Univ. of Idaho

Moscow, ID 83843

T. L. Jones

Department of Agronomy

and Horticulture

New Mexico State University

Las Cruces, NM 88003-0003

W. A. Jury

Department of Soils

University of California

at Riverside

Riverside, CA 90024

P. Kearl

Oak Ridge National Laboratory

Grand Junction Office

Grand Junction, CO 81502

K. Kersch

SAIC, Inc.

101 Convention Ctr. Drive, Suite 407

Las Vegas, NV 89109 
C. T. Kincaid

Pacific Northwest Laboratory

P. O. Box 999, MS K6-77

Richland, WA 99352

R. G. Knowlton

Sandia National Laboratories

P.O. Box 5800, Div 6416

Albuquerque, NM 87185

C. P. Liou

Civil Engineering Department

University of Idaho

Moscow, ID 83843

J. T. McCord

Sandia National Laboratories

Division 6416

Albuquerque, NM 85185-5800

L. M. McDowell-Boyer

Oak Ridge National Laboratory

Grand Junction Office

Grand Junction, CO 81502

C. McLane

ENVIRON International Corp.

4350 N. Fairfax Dr., Suite 300

Arlington, VA 22203

D B. McLaughlin

Department of Civil Engineering

Massachusetts Institute of Technology

Room 48-329

Cambridge, MA 02139

S. A. Mizell

Desert Research Institute

P. O. Box 60220

Reno, NV 89506

D. J. Mulla

Soils Department

Washington State University

Pullman, WA 99164

S. P. Neuman

Dept. of Hydrology and Water Resources

University of Arizona

Tucson, AZ 85721

W. Newberry

U. S. Department of Energy

Nuclear Energy LLW Management

Program, NE-24

Washington, DC 20545
T. J. Nicholson

U. S. Nuclear Regulatory Commission

Division of Engineering Safety

MS NL-005

Washington, DC 20555

J. W. Nyhan

Los Alamos National Laboratory

P. O. Box 1663

Los Alamos, NM 87545

U. S. Park

Science Applications International Corp.

101 Convention Center Drive

Las Vegas, NV 89109

F. L. Parker

4400 Iroquois

Nashville, TN 37205

D. M. Peterson

INTERA Associates, Inc.

8100 Mountain Road NE, Suite 213

Albuquerque, NM

O. A. Plumb

Mechanical and Material Engineering

Washington State University

Pullman, WA 99164-2920

J. Pope

Westinghouse Savannah River Company

Environmental Restoration Program

P. O. Box 616

Aiken, SC 29802

R. W. Prindle

Sandia National Laboratories

Division 6312

P. O. Box 5800

Albuquerque, NM 87185

T. C. Rasmussen

Dept. of Hydrology and Water Resources

University of Arizona

Tucson, AZ 85721

M. Reeves

INTERA Associates, Inc.

6850 Austin Cntr. Blvd.,

Suite 300

Austin, TX 78731 
M. L. Rockhold

Pacific Northwest Laboratory

P. O. Box 999, MS K6-77

Richland, WA 99352

V. C. Rogers

Rogers \& Associates Engineering Corp.

P. O. Box 330

Salt Lake City, UT 84110

A. K. Runchal

ACR, Inc.

3106 Inglewood Blvd.

Los Angeles, CA 90066

B. Sagar

Center for Nuclear Waste Repository

Analyses

Southwest Research Institute

6220 Culebra Rd.

P. O. Drawer 28510

San Antonio, TX 78284

S. G. Schmelling

U. S. Environmental Protection Agency

Robert S. Kerr Environmental Lab

P. O. Box 1198

Ada, OK 74820

M. Silberberg

U. S. Nuclear Regulatory Commission

Office Nuclear Regulatory Research

Washington, DC 20555

J. L. Smoot

Pacific Northwest Laboratory

P. O. Box 999, MS K6-77

Richland, WA 99352

C. J. Suen

Brookhaven National Laboratory

Nuclear Waste and Materials

Technology Division

Upton, Long Island, NY 11973

R. J. Starmer

ERM-Program Management Corp

7926 Jones Branch Drive, Suite 210

McLean, VA 22102

Technical Library

Los Alamos National Laboratory

P. O. Box 1663

Los Alamos, NM 87545
Technical Library

Oak Ridge National Laboratory

P. O. Box X

Oak Ridge, TN 37830

Technical Library

Savannah River Laboratory

P. O. Box 616

Aiken, SC 29802

B. Troutman

Dames and Moore, Inc.

1970 E. 17th St, Suite 111

Idaho Falls, ID 83401

B. J. Travis

Los Alamos National Laboratory

P. O. Box 1663

Los Alamos, NM 87545

S. W. Tyler

Water Resources Center

Desert Research Institute

P. O. Box 60220

Reno, NV 89506-0220

B. L. Roberts

EG\&G Rocky Flats, Inc.

P. O. Box 464

Golden, CO 80402-0464

M. T. van Genuchten

USDA-ARS, U.S. Salinity Laboratory

4500 Glenwood Drive

Riverside, CA 92501

P. van der Heijde

International Groundwater Modeling Center

Colorado School of Mines

Golden, CO 80401-1887

J. Wang

Lawrence Berkely Laboratory

Earth Sciences Division

1 Cyclotron Road,

Berkely, CA 94720

A. W. Warrick

University of Arizona

Dept. of Soil and Water Science

Tucson, AZ 85721

E. P. Weeks

U. S. Geological Survey

Federal Center, MS 413

Denver, CO 80225 
M. Weinstein

U. S. Nuclear Regulatory Commission MS NL/S-260

Washington, DC 20555

P. J. Wierenga

University of Arizona

Dept. of Soil and Water Science

Tucson, AZ 85721

D. C. Wiggert

Michigan State University

A120 Engineering Research Complex

East Lansing, Michigan $\mathbf{4 8 8 2 4}$

J. L. Wilson

New Mexico Institute of Mining

and Technology

Dept. of Geosciences

Socorro, NM 87801

Westinghouse Hanford Company

P. O. Box 1970

Richland. WA 99352

J. D. Davis, MS H4-54

R. Khaleel, MS H4-54

J. C. Sonnichsen, MS H4-54

A. Yu

Westinghouse Savannah River Company

Savannah River Laboratory

P. O. Box 616

Aiken, SC 29802

QNSITE

DOE-ID

M. C. Bennett

L. A. Green

EG\&G Idaho, Inc.

R. C. Arnett

R. G. Baca

L. C. Hull

J. M. Hubbell

C. B. Lee

J. A. Logan

S. O. Magnuson

S. J. Maheras

J. N. McCarthy

J. W. Mc Connell
R. L. Nitschke

H. D. Nguyen

R. R. Seitz

J. B. Sisson

C. S. Smith

A. J. Sondrup

L. V. Street

INEL Technical Library

Westinghouse Idaho Nuclear Co. Inc.

T. R. Thomas

U.S. Geological Survey

J. R. Pittman

L. J. Mann 

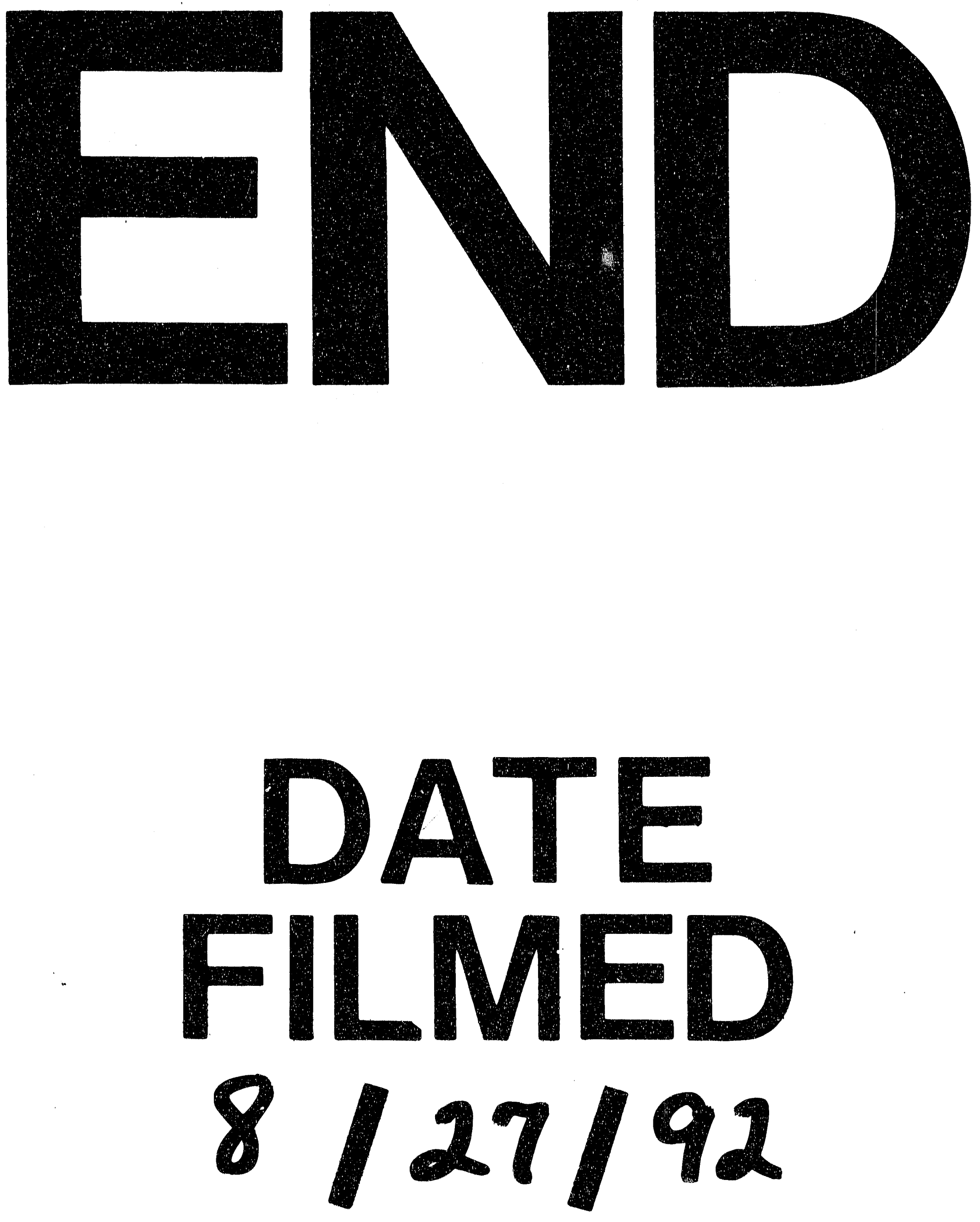
